\title{
Evaluation Criteria and Test Methods for Electrochromic Windows
}

A. W. Czanderna

Solar Energy Research Institute

Carl M. Lampert

Lawrence Berkeley Laboratory

Berkeley, CA 94720

July 1990

Prepared under task number SB913041

Solar Energy Research Institute

A Division of Midwest Research Institute

1617 Cole Boulevard

Golden, Colorado 80401-3393

Prepared for the

U.S. Department of Energy

Contract No. DE-AC02-83CH10093 


\title{
NOTICE
}

This report was prepared as an account of work sponsored by an agency of the United States government. Neither the United States government nor any agency thereof, nor any of their employees, makes any warranty, express or implied, or assumes any legal liability or responsibility for the accuracy, completeness, or usefulness of any information, apparatus, product, or process disclosed, or represents that its use would not infringe privately owned rights. Reference herein to any specific commercial product, process, or service by trade name, trademark, manufacturer, or otherwise does not necessarily constitute or imply its endorsement, recommendation, or favoring by the United States government or any agency thereof. The views and opinions of authors expressed herein do not necessarily state or reflect those of the United States government or any agency thereof.

\author{
Printed in the United States of America \\ Available from: \\ National Technical Information Service \\ U.S. Department of Commerce \\ 5285 Port Royal Road \\ Springfield, VA 22161
}

Price: Microfiche A01

Printed Copy A04

Codes are used for pricing all publications. The code is determined by the number of pages in the publication. Information pertaining to the pricing codes can be found in the current issue of the following publications which are generally available in most libraries: Energy Research Abstracts (ERA); Government Reports Announcements and Index (GRA and I); Scientific and Technical Abstract Reports (STAR); and publication NTIS-PR-360 available from NTIS at the above address. 


\section{PREFACE}

In keeping with the national energy policy goal of fostering an adequate supply of energy at a reasonable cost, the U.S. Department of Energy (DOE) supports a variety of programs to promote a balanced and mixed energy resource system. The mission of the DOE Solar Buildings Research and Development Program is to support this goal by providing for the development of solar technology alternatives for the buildings sector. It is the goal of the program to establish a proven technology base to allow industry to develop solar products and designs for buildings that are economically competitive and can contribute significantly to building energy supplies nationally. Toward this end, the program sponsors research activities related to increasing the efficiency, reducing the cost, and improving the long-term durability of passive and active solar systems for building water and space heating, cooling, and daylighting applications. These activities are conducted in four major areas: (1) Advanced Passive Solar Materials Research, (2) Collector Technology Research, (3) Cooling Systems Research, and (4) Systems Analysis and Applications Research. Area (1) is pertinent to this report.

Advanced Passive Solar Materials Research. This activity area includes work on new aperture materials and devices for controlling solar heat gains and enhancing the use of daylight for building interior lighting purposes. It also encompasses work on low-cost thermal storage materials that have high thermal storage capacity and can be integrated with conventional building elements and work on materials and methods to transport thermal energy efficiently between any building exterior surface and the building interior by nonmechanical means.

Collector Technology Research. This activity area encompasses work on advanced low- to medium-temperature (as high as $180^{\circ} \mathrm{F}$ useful operating temperature) flat-plate collectors for water and space heating applications, and medium- to high-temperature (as high as $400^{\circ} \mathrm{F}$ useful operating temperature) evacuated-tube concentrating collectors for space heating and cooling applications. The focus is on design innovations using new materials and fabrication techniques.

Cooling Systems Research. This activity area involves research on highperformance dehumidifiers and chillers that can operate efficiently with the variable thermal output and delivery temperatures associated with solar collectors. It also includes work on advanced passive cooling techniques.

Systems Analysis and Applications Research. This activity area encompasses experimental testing, analysis, and evaluation for solar heating, cooling, and daylighting systems for residential and nonresidential buildings. This involves system integration studies; the development of design and analysis tools; and the establishment of overall cost, performance, and durability targets for various technology or system options.

This work relates to Advanced Passive Solar Materials Research on the durability of electrochromic (EC) windows for controlling solar heat gains and enhancing the use of daylight for building interior lighting purposes. By discussing the test methods for evaluating EC windows and summarizing what is known about their performance degradation, a set of recommendations is given for advancing durability testing of EC windows. Representative literature 
citations are provided as a means for reaching the conclusions about durability testing, and to provide guidance for those who seek more depth about the complexity of EC windows.

The work was performed at the Lawrence Berkeley Laboratory in the Applied Science Division, and the Photovoltaic Measurements and Performance Branch at the Solar Energy Research Institute. The authors appreciate the financial support by the Assistant Secretary for Conservation and Renewable Energy, Office of Solar Heat Technologies, Solar Buildings Division, United States Department of Energy under contracts DE-AC02-83CH10093 and DE-AC03-76SF00098. 


\section{SUMMARY}

The primary purposes of this report are to summarize the test methods used for evaluating electrochromic (EC) windows, to summarize what is known about degradation of their performance, and to recommend methods and procedures for advancing EC windows for buildings applications.

A brief overview is provided for the applications of EC devices in various technologies with a focus on buildings. The parameters used for testing EC windows are organized into evaluation criteria; performance criteria; and testing methods for laboratory (research), prototype, and durability evaluation. Key technical issues that have emerged are organized into the categories of practical windows, durability testing, and fundamental mechanisms. A brief background summarizes the interest, potential, physical configuration, and operation of an EC window. Evaluation criteria for ranking candidate EC device materials and for complete candidate EC windows are discussed briefly.

The performance criteria for EC windows are then organized into two major sections. In the first section, performance parameters used in research investigations are summarized. The parameters are grouped into optical properties, injected charge or ions, open circuit memory, cycle energy, response time, and substrate effects. A list of questions to be resolved for the laboratory performance evaluation is presented. The most important parameters needed to evaluate an EC window are summarized, i.e., optical properties of $T(\lambda), R(\lambda)$, $A(\lambda)$; injected charge/unit volume correlated with the optical properties; I-V curves again correlated with the optical properties, and the time-temperature dependence of the response time.

The second major discussion section deals with test methods for evaluating the durability of complete EC windows. Performance losses result from imposed degradation stresses and are summarized under the categories of degradation effects, degradation modes, and degradation mechanisms. Degradation stresses include UV, humidity, temperature, air, pollutants, thermal shock, cyclic temperature, cyclic charge injection, and bleaching. Degradation modes can result from thermal shock, prolonged non-use, constant elevated temperatures, and various cyclic changes. Degradation effects include gas generation in some devices, humidity effects, internal water formation, secondary reactions, photoreactions, quenching (fading of color), volume changes, and temperature (dependent) effects. Established degradation mechanisms include film dissolution, corrosion, transparent conductor etching, and hydrogen embrittlement.

Performance measurements for real-time and accelerated life testing are then discussed. These include measuring the transmittance and reflectance (wavelength dependence) of an EC window in the colored and bleached states, the atomic percent of injected charge, and the time dependence of the change in percent transmittance during coloring and bleaching. The proposed methods and procedures are summarized for real-time and accelerated life testing.

As a conclusion, a set of recommendations is made for advancing EC window technology, especially for durability testing. These recommendations are preliminary but provide a suitable foundation for further refinement. 
TABLE OF CONTENTS

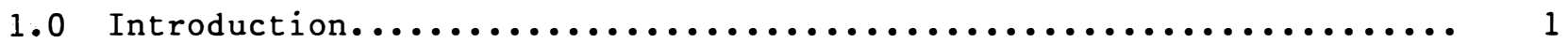

1.1 \#0bjectives..................................." 1

1.2 \#Applications of EC Windows in Technologies.................. 1

1.3 Relationship Among Evaluation Criteria, Performance Criteria, and Testing Methodologies for EC Windows................... 2

1.4 Key Technical Issues for Evaluation Criteria and Test Methods for EC Windows.............................. 3

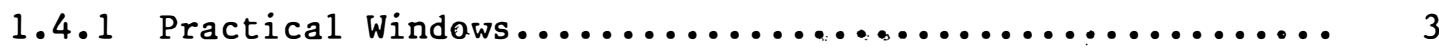

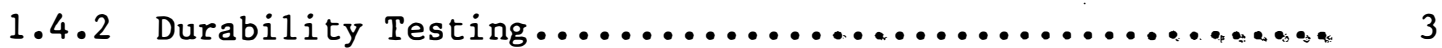
1.4.3 Fundamental Mechanisms.............................. 3

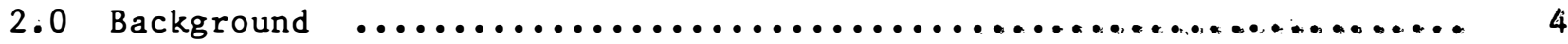

3.0 Evaluation Criteria for EC Windows...................... 7

3.1 Criteria for Ranking Candidate Materials................ 7 3.1.1 Ionic Conducting Layer: Solid State Inorganic or Polymeric.................................. 8

3.1.2 Electrode and Counterelectrode Layer Materials......... 8 3.1.3 Transparent Conducting Layers........................ 8 3.2 Criteria for Ranking Complete Candidate EC Windows.......... 8

4.0 Performance Criteria for EC Windows...................... 11

4.1 Parameters Measured/Used to Establish EC Window Performance.... 12 4.2 \#Performance Criteria Expected for EC Windows for Buildings

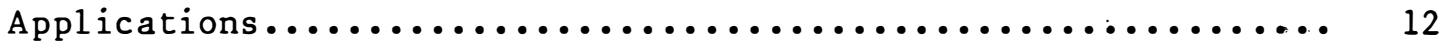

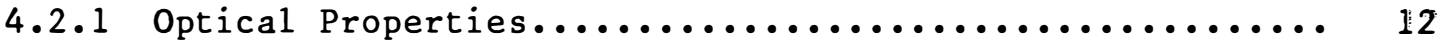
4.2.2 Ion Insertion, Color Centers, or Injected Charge....... 16 4.2.3 Open Circuit Memory and Calculation of Cycle Energy..... 17

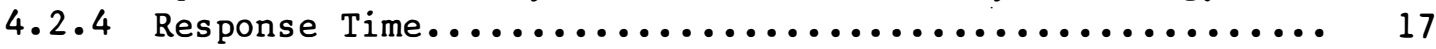

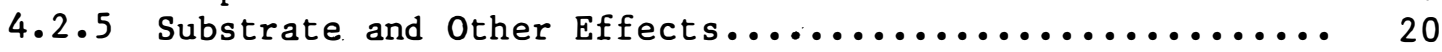

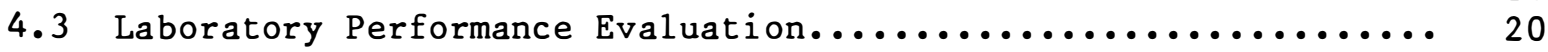
4.4 Ranking of the Most Important Parameters from Table 4-1...... 21

5.0 Test Methods and Procedures for Evaluating EC Window Stability and/or Durability.................................. 22

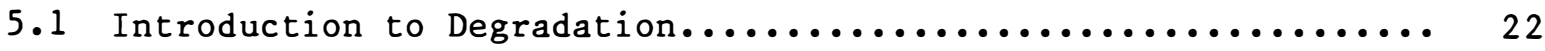

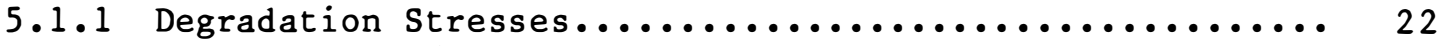

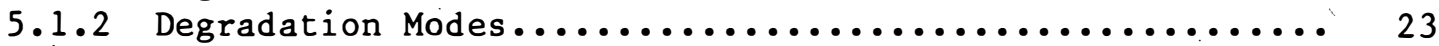

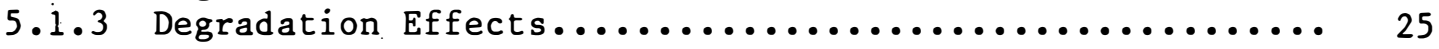

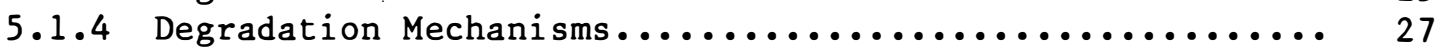

5.1 .5 Other Degradation Problems...................... 30

5.1.6 Summary of Degradation Stresses, Modes, Effects, and

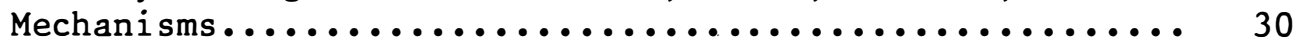


TABLE OF CONTENTS (Concluded)

5.2 Performance Measurements for Real-Time and Accelerated Life Testing.................................... 33

5.2.1 Wavelength Dependence of Transmittance and Reflectance in Colored/Bleached States....................... 33

5.2.2 Atomic Percent of Injected Charge.................. 33

5.2.3 Time Dependent Change in the Transmittance and Reflectance During Coloring/Bleaching............. 34

5.3 Methods/Procedures for Real-Time Testing................. 36

5.3.1 Cyclic Tests Emphasizing Electrical Properties of

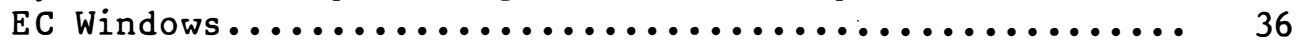

5.3.2 Cyclic Tests Under Use or Storage Conditions.......... 36

5.4 Methods and Procedures for Accelerated Testing.............. 37

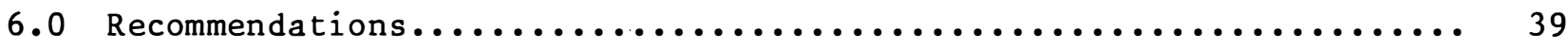

7.0 Acknowledgments................................ 43

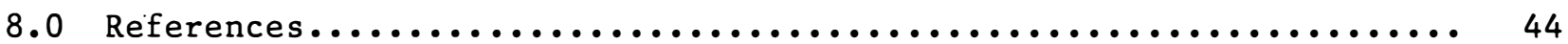




\section{LIST OF FIGURES}

2-1. Schematic cross section depicting generalized EC window designs.... 5

4-1. Schematic structure of a cathodic EC device................. 11

4-2. Optical absorption in amorphous and crystalline $\mathrm{wO}_{3} \ldots \ldots \ldots \ldots$

4-3. Response of an idealized electrochromic tungsten oxide switching device.......................................... 19

5-1. Relationship between contrast ratio and 1 ifetime for a tungsten oxide electrochromic device (ITO/a-WO 3 / electrolyte/metal)....... 24

5-2. Long term cycling of tungsten oxide devices ( $1 \mathrm{TO} / \mathrm{a}-\mathrm{WO}_{3} / \mathrm{LiClO} \mathrm{L}_{4}+$ Redox/ITO)......................................... 24

5-3. The decline in charge capacity (charge per unit area) with time and temperature for a tungsten oxide electrochromic device $\left(\mathrm{ITO} / \mathrm{a}-\mathrm{WO}_{3} / \mathrm{LiClO}_{4}+\operatorname{Redox} / \mathrm{ITO}\right) \ldots \ldots \ldots \ldots \ldots \ldots \ldots \ldots \ldots \ldots \ldots \ldots \ldots \ldots$

5-4. Etch rate (R) vs $\mathrm{pH}$ for $\mathrm{WO}_{3}$ films immersed in different buffered electrolyte solutions................................ 29

5-5. Optical transmission spectra of a Li $\mathrm{WO}_{3}$ thin film on soda-1ime-

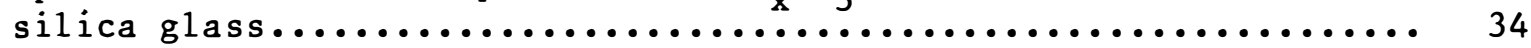

5-6. Change in absorbance with switching time before and after

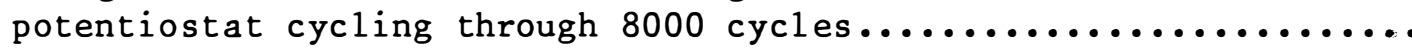

5-7. Temperature dependence of the coloration and bleaching times of 200- $\AA$-thick sputtered iridium oxide films deposited on tantalum and iridium substrates, and studied in concentrated acidic and basic aqueous solutions :......................

5-8. A comparison of the relative spectral distribution of power from sunlight at air mass 1.5 (A), Weather-Ometer (B), and QUV (C)

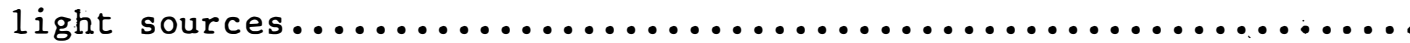

6-1. Flow of EC window testing from (1) laboratory research and evaluation, to (2) prototype testing, to (3) durability testing,

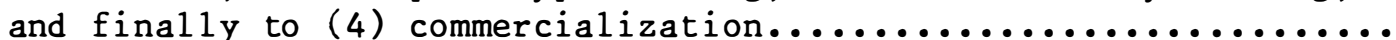




\section{LIST OF TABLES}

Page

3-1. Performance Criteria for EC Windows..................... 10

4-1. Parameters Related to Performance Criteria Expected for EC Windows-Buildings Applications........................ 13

5-1. Matrix of Various Studies in which a Degradation Mechanism, Effect, or Mode has Resulted from Various Degradative Stresses or Conditions Imposed........................ 31

5-2. Matrix of Various Studies in which a Specific Device has had Various Degradative Stresses or Conditions Imposed............. 32

6-1. Categorization of Parameters and Measurements for Different Stages of EC Window Research and Development................. 41

6-2. Recommended Test Matrix at Various Stages of EC Window Research

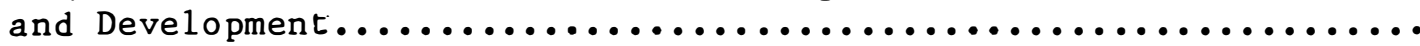




\section{ABBREVIATIONS AND ACRONYMS}

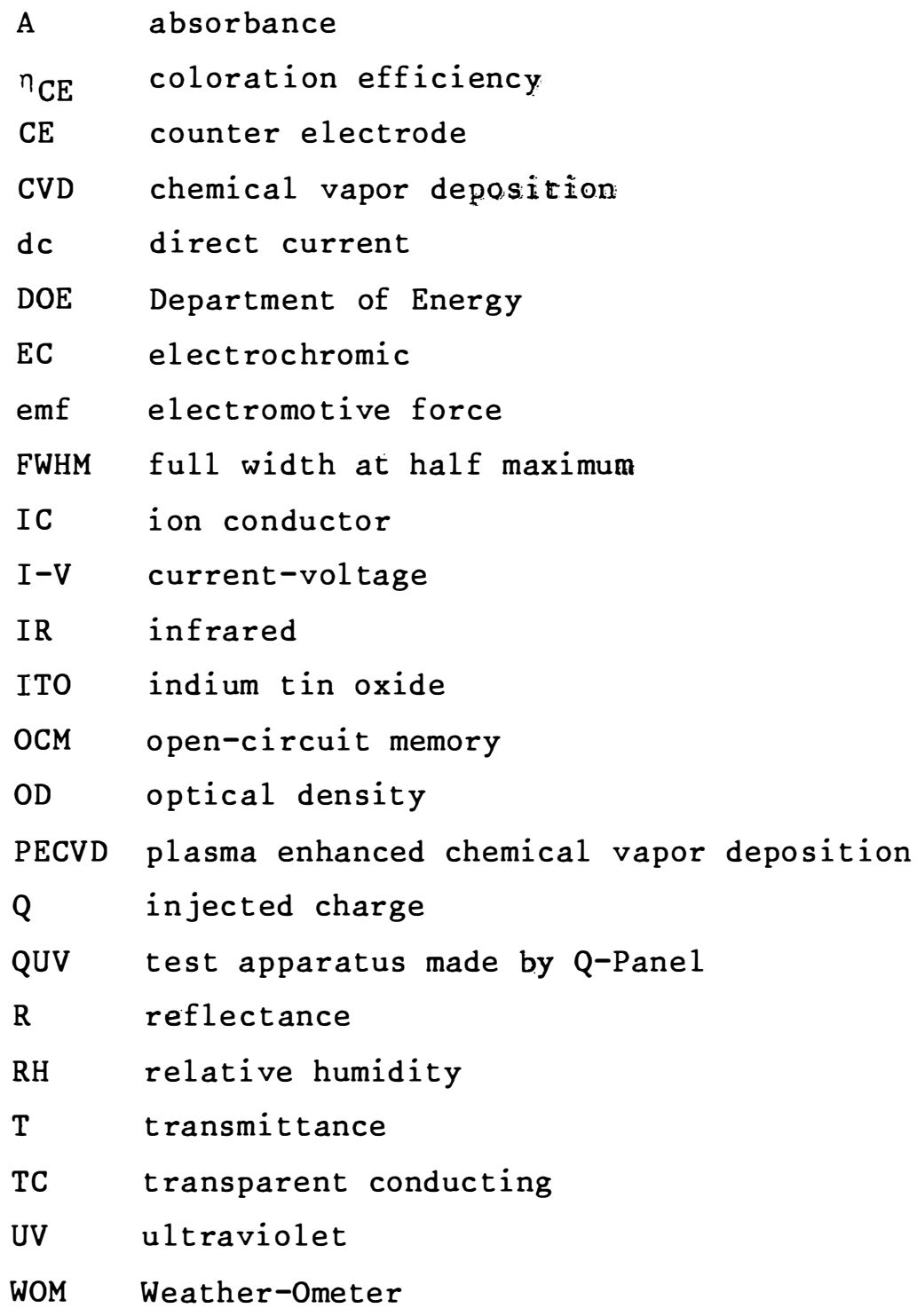




\subsection{INTRODUCTION}

This report serves two primary purposes. The first is to summarize the current state-of-the-art test methods used to evaluate electrochromic (EC) windows. The second, purpose is to recommend methods and procedures to test EC windows for buildings applications. Material presented here is also primarily directed toward those who are active in EC window research and development. For the benefit of those who are interested in more depth, representative references are cited as a guide for gaining insight into the considerable complexity of EC window technology. EC device use in buildings, as well as suggestions for low-volume and high-cost applications, will also be presented.

\subsection{Objectives}

The objectives of this report are to present adequate background about EC window applications, to identify general evaluation criteria, to 1 ist expected performance criteria, to identify and discuss methods needed for testing prototype EC windows in laboratory research including their durability, to rank and recommend methods for evaluating laboratory and prototype EC windows, and to make recommendations for advancing the state of the art beyond the laboratory stages through the prototype and commercial product stages.

\subsection{Applications of EC Windows in Technologies}

A number of technology areas have been identified in which EC windows have clear potential for applications. From a U.S. Department of Energy (DOE) perspective, the goal is to conserve energy in buildings by using EC glazings. Other applications include use in eyeglasses, information displays, aerospace, and vehicles. Initially, the likely market penetration will involve specialty products with high cost and low volume, with subsequent penetration into the high-volume and low-cost buildings applications.

Window glass production in the United States is about four billion square feet per year for buildings, with about 700 million square feet used in sealed insulating windows (Cunningham, 1986). Although no definitive analysis of energy savings potential has been made for switchable windows, some analyses (Bartovics, 1984; Bryan et al., 1984) have shown that several $\mathrm{kWh} / \mathrm{ft}^{2}$-year could be saved by use of a well-programmed, automatically-controlled, switchable window in commercial and residential buildings. The energy savings potential is more than 100 billion $\mathrm{kWh} / \mathrm{yr}$ (current total U.S. energy consumption is about $24 \mathrm{trillion} \mathrm{kWh} / \mathrm{yr})$. Details about the energy savings potential are available (Selkowitz and Lampert, 1990). A reduction will also occur in the peak power demand for air conditioning including HVAC sizing.

EC windows are highly desirable for providing both a net energy benefit and design options for commercial builders. However, industry may perceive EC windows as a high technology approach for buildings applications, and some manufacturers are slow to innovate. Currently, technological development of an EC window is a high-risk project for industry but they are strongly supportive of DOE-funded research. The nost likely productive collaborations will result from interactions with a selected group of manufacturers who recognize the scope of the problems and potential market. Ultimate acceptance will depend on a clear demonstration of economic and technical feasibility. 
A recent communication (Wolsky et al., 1988) stated,

\begin{abstract}
"The building industry will most likely not be attracted to using EC window until research and development results in a practical demonstration of an EC window of about $1 \mathrm{ft}^{2}$ that is functional, aesthetically pleasing, and has the potential for economic scaleup and long-term durability. The device must demonstrate that high production rates and an economical installed cost can be achieved with industrial production, at about twice the cost of present low E coated windows. Economic issues for scale-up must be kept in excellent perspective, both for materials and processes under study. Any EC window project that is using materials with unacceptable aesthetics to building architects or low-potential for scale-up of the process will not have any reasonable chance for adoption and production by industry."
\end{abstract}

The likely scenario for market penetration will be for specialty glass products or where there are less stringent requirements for mass use. These may include use for automobile sun roofs (high cost), "status" buildings applications. (less stringent requirements), and other custom building applications. Near-term specialty and custom applications will not. only help general consumer acceptance but provide valuable data about unforeseen technical issues, durability, and manufacturing problems.

\title{
1.3 Relationship Among Evaluation Criteria, Performance Criteria, and Testing Methodologies for EC Windows
}

A large number of parameters are currently used by various research groups. These parameters are organized in this report according to evaluation criteria, performance criteria, and testing methods. Evaluation criteria include those parameters primarily influencing commercial feasibility. These criteria include the parameters for ranking the materials used in each component layer, as well as for a complete EC window. Performance criteria deal specifically with the physical properties of EC windows that must be met as one component of meeting commercial feasibility requirements. These criteria also deal with the ranges through which measurements are made for laboratory evaluation. Testing methods use the essential performance criteria to evaluate the durability for a prototype window. Performance losses can result from imposed durability stresses and can be categorized as degradation effects, modes, and mechanisms. Testing methods also include the conditions required for realtime and accelerated testing of EC windows. The parameters and measurements can be categorized as laboratory research, prototype evaluation, durability evaluation, and commercial feasibility. These categories are outlined in Section 6.0 .

We especially emphasize that the evaluation and performance criteria in this report are developed for buildings applications. Different criteria will likely be required when using EC devices and/or windows for other applications, e.g., automotive sunroofs, aerospace windows, and rear-view mirrors (Lampert and Granqvist, 1990). Since the other applications may require using the same methodologies and test procedures summarized in this report, this report may also serve as a suitable foundation for applications other than for buildings. 


\subsection{Key Technical Issues for Evaluation Criteria and Test Methods for EC Windows}

Technical issues that have surfaced while preparing this report have been organized into those dealing with practical windows, durability, and fundamental mechanisms. The following list of issues is not intended to be complete for a comprehensive research program on EC windows. Those listed for durability testing and some of those for practical windows provide a focus for discussion in this document.

\subsubsection{Practical Windows}

- What common criteria are being (or should be) used to compare EC window performance?

- What methods should be used to model EC window performance?

- How does an EC window perform? - How does performance depend on device size, sheet resistivity, and the applied voltage?

- What aesthetics are required?

- What economics are required?

\subsubsection{Durability Testing}

- What performance parameters could be measured, which ones are redundant, and which ones are essential for durability studies?

- What are the maximum and minimum testing temperatures for various applications?

- What methodologies need to be employed for real-time and accelerated life testing.

- At what stage of EC window research and development should durability issues be addressed?

\subsubsection{Fundamental Mechanisms}

- What is the mechanism of ion injection? The details are not understood even though a transport model has been developed.

- How does an ion cross an interface? This process is not understood.

- What causes residual coloration and does it limit durability?

- Is there a loss in dynamic range of injected charge, percent transmittance, and stability on cyclic switching; are these losses related to durability or merely a loss in performance? 


\subsection{BACKGROUND}

There is considerable interest in the research and development of materials and devices that can be used for optical switching of large scale glazings. Several potential switching technologies are available for glazings, including those based on electrochromism, thermochromism, photochromism, 1iquid crystals, and physio-optic phenomena. One of the most promising technologies for optical switching is electrochromism. First, EC windows exhibit a memory and require power only to change their coloration and minimal power to maintain a colored (or bleached) state; this technology is in contrast to liquid crystals. Second, EC windows may have their optical properties changed at will, in contrast to devices based on thermochromism and photochromism. Furthermore, these glazings are subject to automation because of their operating mechanisms. Finally, they consume low amounts of power for switching and minimal amounts of power to maintain them in a given optical state.

Although EC windows have great potential, they also have a generous share of technical uncertainties and problems. A few prominent degradative effects have been observed for many different devices, e.g., residual coloration, 1 oss of dynamic range, and loss of stability of the device during long-term cyclic switching. The origins of the effects are only partially understood at this time. Also, it is very important to note that these effects depend upon the conditions of testing and in some cases are not permanent. While it is too early to discuss why these effects occur, it is important to discuss these observations as the research on devices moves forward. With this report we hope to better understand stability in these devices and to comment on test methods used, lifetime, and criteria for evaluating EC windows.

EC devices function by the reversible injection/ejection of both electrons and ions in/out of an EC material. A typical EC reaction for a cathodic coloring material is: a- $\mathrm{WO}_{3}+\mathrm{xH}^{+}+\mathrm{xe}^{-} \rightarrow \mathrm{a}-\mathrm{M}_{\mathrm{x}} \mathrm{WO}_{3}$, where $\mathrm{M}=\mathrm{Li}^{+}, \mathrm{H}^{+}, \mathrm{Na}^{+}$, etc., $\mathrm{WO}_{3}$ is transparent, and $\mathrm{M}_{\mathrm{x}} \mathrm{WO}_{3}$ is blue colored. A typical anodic coloration reaction is: $\mathrm{Ni}(\mathrm{OH})_{2} \rightarrow \mathrm{NiOOH}+\mathrm{H}^{+}+\mathrm{e}^{-}$, where $\mathrm{Ni}(\mathrm{OH})_{2}$ is transparent, and $\mathrm{NiOOH}$ is bronze colored. Devices are designed to store ions and permit them to be transported back and forth into the EC layer when a potential is applied.

To understand how devices perform, degrade, and fail, we must discuss the structure and materials of different devices. The EC device is generally composed of 4 or 5 layers. There are five general structural types, designated as Types A, B, C, D, or $\mathrm{E}$ in Figure 2-1.

The structures of all five types begin and end with a transparent electronic conductor layer on a glass substrate. Typically, this conductor is indium tin oxide, $\mathrm{In}_{2} \mathrm{O}_{3}$ : Sn (ITO) or tin oxide doped with antimony or fluorine, $\mathrm{SnO}_{2}: \mathrm{Sb}$ or $\mathrm{SnO}_{2}: \mathrm{F}$. Since the liquid and electrolyte devices ( $\mathrm{A}$ and $\mathrm{B}$, respectively in Figure 2-1) are unlikely candidates for buildings applications, the remainder of our generalized description is for types C, D, and E. The second layer is the EC layer. It has both ionic and electronic conduction. The typical EC layer can be amorphous or crystalline tungsten oxide, a- $\mathrm{WO}_{3}$ or $\mathrm{c}-\mathrm{WO}_{3}$; iridium hydroxide, $\operatorname{Ir}(\mathrm{OH})_{2}$; or nickel hydroxide, $\mathrm{Ni}(\mathrm{OH})_{2}$. The most-used material is a- $\mathrm{WO}_{3}$. The third layer is an ion conductor (IC). In many EC devices prepared for laboratory studies, liquid electrolytes have been used, but this layer should be a solid electrolyte for buildings. The fourth layer is the counter 
Transparent conductor-------- TC Electrochromic---------------- EC Ion conductor-IC/Electrolyte- EL Ion storage----.------------- IS

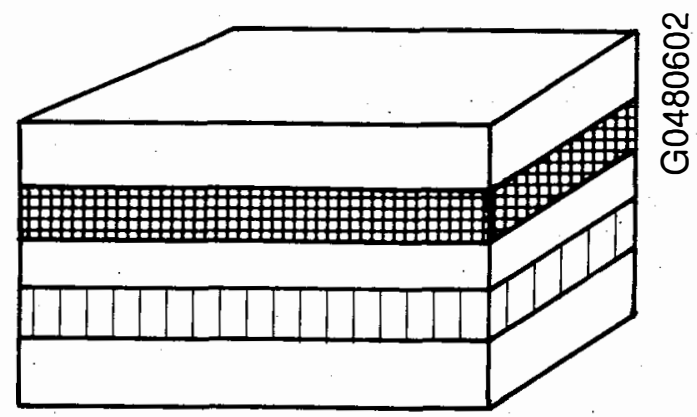

A. Liquid Device

B.Electrolyte Device

C. Combined Ion Storage and Conductor

D. Complementary Electrochromic

E. Ion Storage Layer Device

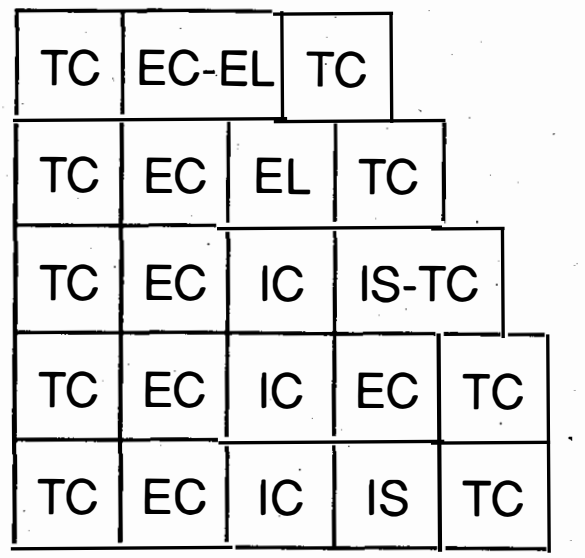

Figure 2-1. Schematic cross section depicting generalized EC window designs

electrode (CE) material and may be another EC material or an ion-storage material. In the combined ion storage and conductor designs, the fourth layer is a combined electronic conductor and ionic storage medium, thus eliminating the fifth layer. The ion storage layer device (Type E) is the most commonly fabricated device. In the complementary device design (type $D$ ), the counter electrode and working electrode are both EC materials, where one colors anodically and the other cathodically; in this way they color together and bleach together. By using two electrochromic materials one can increase the optical density of the device over that of the single material. In the Nissan device (Kase et al., 1986) for example, cathodic a-WO 3 and anodic Prussian Blue, $\left(\mathrm{Fe}_{4}(\mathrm{Fe}(\mathrm{CN}))_{6}\right)_{3}$ are coupled. But by doing so, they introduce an electrochemical imbalance. To make a practical device, another electrode must be added to periodically adjust for the charge imbalance in the device. Probably the most successful complementary device is based on anodic $\mathrm{IrO}_{2}$ or $\operatorname{Ir}(\mathrm{OH})_{2}$ and cathodic a- $\mathrm{WO}_{3}$. An example of this device has been made by EIC Laboratories. The high cost and limited supply of iridium preclude its consideration for practical EC windows, but it may be used for specialized applications such as in aircraft windows.

A major problem with current EC window technology is with the electrolyte. Both inorganic and polymeric solid electrolytes can be considered, but the electrolytes must not compromise the economics of manufacturing and potential durability of the units. Inorganic electrolytes may require special 
deposition processes for successful preparation (e.g., high lithium ion mobility in a material may preclude successful ion sputtering of that material). The mechanisms of ion transport are incompletely understood in the electrode materials and need further study, especially as detailed below. More details about the ion conducting layer are available (Lampert and Granqvist, 1990).

Some researchers believe lithium ions are preferable to $\mathrm{H}^{+}$for ion transport because of the difficulty with controlling the $\mathrm{H}^{+}$ion concentration. Other ions (e.g., $\mathrm{Na}^{+}, \mathrm{K}^{+}$, and $\mathrm{Ag}^{+}$) have also been used successfully. Battery researchers have a wealth of experience with $\mathrm{Li}^{+}$-conducting electrolytes and this resource should be tapped when additional research on solid polymeric electrolytes for EC windows is undertaken. Other researchers favor using $\mathrm{H}^{+}$ and research is underway with devices using either $\mathrm{Li}^{+}$or $\mathrm{H}^{+}$. As described in Section 5, one of the key issues with $\mathrm{H}^{+}$-based devices may be the presence of water. In either (or any other) case, ion transport data need to be known for establishing the solid IC layer thickness, which can be calculated using the optical properties of candidate IC materials and thicknesses. These computer calculations, which can be performed using established multilayer analysis modeling of the optical transmittance and reflectance, will be helpful for choosing the thicknesses of the various layers, and serve as a useful guide for preparing EC device test specimens with optimum layer thicknesses. (If, for example, vacuum deposition processes are adopted, these thicknesses are required for economic projections because of the capital investment of deposition units, throughput, and process-dependent properties of films).

EC windows will experience the greatest temperature fluctuations when used in a configuration for preventing solar gain (i.e., absorbing and reflecting photons with the EC layer). Research materials should retain their performance and have adequate lifetimes for the temperature extremes planned for this configuration. Furthermore, the temperature dependence of the ion transport in both the electrolyte and electrode materials must be studied and reported. These data are needed to address the crucial issue of how temperature will change the performance of real-world devices. Except for early work, (e.g., Faughnan and Cranda11, 1980), the ion transport data in EC window materials have all been reported at room temperature. Recently, some temperature-dependent results have been obtained for battery applications (Weppner and Schultz, 1987). 


\subsection{EVALUATION CRITERIA FOR EC WINDOWS}

The criteria for evaluating EC windows are treated in two broad categories. The first includes the criteria for ranking candidate materials used in the various layers, i.e., the ionic-conducting layer, the electrode and counterelectrode materials, and the transparent conducting layers (Section 3.1). An excellent summary of the candidate layer materials was made in 1984 (Lampert, 1984), and an update of electrochromic displays was made 2 years later ( $0 i$, 1986) In the second category (Section 3.2), criteria for complete windows have been summarized by a number of investigators, e.g., Benson et a1., 1984 .

\subsection{Criteria for Ranking Candidate Materials}

The candidate material chosen for each layer defines the entire device, i.e., Cover//TC/EC/IC/CE/TC//Substrate. However, the "best" material for each layer may not necessarily be chosen because of other factors. These include the potential for mechanical strains from thermal expansion mismatches, interface reactions, and the influence of the deposition processes; the latter will be discussed further below. Once each layer material is chosen, further requirements include the device size (area and thickness); the optimized layer thickness to yield the required optical properties; the density of the EC, CE, and IC materials; and the number of injected ions per unit volume. The latter should lead to the change in transmittance required for the application.

The process used to deposit the layers of materials is important. First, the deposition of multilayers should be done in the laboratory using processes that have potential for economical, large-scale production. Alternatively, a good device could be produced by several consecutive processes and then an economic, scaled-up method would be a development objective. This is because deposition techniques influence the coating structure, morphology, composition, and properties.

Several deposition techniques have been used to form the layers in EC devices. These include chemical vapor deposition (CVD), plasma enhanced CVD (PECVD), vacuum evaporation, RF and dc sputtering, sol gel processes, solution coating, and electrochemical deposition. Each of these techniques have advantages and disadvantages related to capital investment, process cost, deposition rate and conditions, materials compatibility, and film properties. A recent report (Wolsky et al., 1988) states, "There are no technical problems associated with using a vacuum coater with mixed deposition procedures, e.g., use PECVD for rapid deposition of thick coatings and some other deposition process where PECVD may be difficult to use. For example, PECVD for forming the IC layer may be difficult, but using PECVD for all of the other layer(s) may be feasible, as has been discussed (Benson et al., 1987). Magnetron sputtering and PECVD have been combined in existing vacuum deposition practice when the pressures are not different by more than $30 \%-40 \%$." As our solar experience using the latter technology has shown, the mass production of large area arrays of a-Si:H photovoltaic cells (Carlson and Wronski, 1976; Luft'and Tsuo, 1988) has resulted in an order-of-magnitude reduction in the cost of producing solar cells (Madan, 1986). It now may be appropriate to critically review the film preparation processes for EC windows, and to identify the "best" deposition process(es). 


\subsubsection{Ionic Conducting Layer: Solid State Inorganic or Polymeric}

This layer serves as the vehicle for ion transport between the electrode and counter electrode. It should be colorless in the visible spectrum, thermally stable, and UV stable. For device design, the transport rate and its temperature dependence must be known so a layer thickness can be chosen. Knowledge of the transport mechanism may help avoid choosing materials that will have "designed-in" durability problems. More detail about the need for this layer is given in Section 2.0 .

\subsubsection{Electrode and Counter Electrode Layer Materials}

The EC and CE materials must provide the appropriate absorption centers when an applied voltage results in an injected charge. For this case, electrochemical "battery" criteria apply, i.e., an EC window is simply a solid state battery that can have its transparency changed. The other important criteria for ranking $E C$ and $C E$ materials include the counter ions preferred, choosing materials in crystalline or amorphous states, coloring/bleaching of both EC and $\mathrm{CE}$, the influence of cyclic switching, stability (i.e., not oxidizable), and reversibility. Some devices studied have acknowledged prohibitive materials costs (Cogan and Rauh, 1990). There are a number of well documented weaknesses in the $\mathrm{WO}_{3}$ system (Faughnan and Cranda11, 1980). Many researchers have said the presence of water in devices should be minimized. Prototype devices are being made using $\mathrm{Li}^{+}$and $\mathrm{H}^{+}$, with research on $\mathrm{Li}^{+}$-based devices increasing (Goldner et al., 1989; Cogan and Rauh, 1989).

\subsubsection{Transparent Conducting (TC) Layers}

The primary criteria for the TC layers are sufficient conductivity (or low sheet resistance) for the device size anticipated and impermeability to the ionic charge (or injected charge) in the EC and $\mathrm{CE}$ layers. ITO meets the first criterion, but recent research with $\mathrm{Li}^{+}$ions indicates degradation of the ITO because of $\mathrm{Li}^{+}$ion insertion (Cogan and Rauh, 1989).

\subsection{Criteria for Ranking Complete Candidate EC Windows}

A number of criteria must be considered when ranking a complete EC window to identify the most promising candidate(s). These are 1 isted below in an order that serves as a reasonable sequence for consideration.

Designed Function. Does the designed function serve the performance needs of an EC window for the particular application. For example, does it function in a variable reflection, variable absorption, or mixed reflection/absorption mode? Does it offer the optical properties desired for both the visible and near-infrared (IR).

Aesthetically Acceptable. The window should have a neutral color (e.g., bronze, grey, tan) with minimal change in color upon switching. Glass companies and architectural firms can make valuable input here. The device should also be uniform in optical density over areas of greater than $1 \mathrm{~m}^{2}$ during switching; e.g., blotchiness must be avoided.

Economic. The EC window should provide payback in less than 5 years based on energy savings plus additional "amenity" values (e.g., replacement for 
draperies, etc.). This goal many translate into production costs of up to several dollars per square foot for the coating.

Minimum Performance Expectations. Is the EC window effective and is the anticipated energy benefit derived? The transmittance should range between $70 \%$ to $80 \%$ (bleached) to below $10 \%$ to $20 \%$ in the visible transmittance spectrum (for the added value of privacy). For solar transmittance, the range should be from about $70 \%$ (bleached) to below 10\% (colored), but this depends on the application. The operating temperature range should be $0^{\circ}$ to $70^{\circ} \mathrm{C}$ or broader. A switching time $\leq 60 \mathrm{~s}$ for the change in solar transmittance is acceptable.

Minimum Test Specimen Size. The laboratory-studied prototypes need to be large enough to assure scaleability to a production size. Prototypes for durability testing may range from $0.1 \mathrm{~m}^{2}$ to $5 \times 5 \mathrm{~cm}$ depending on the stage of testing prior to developing the $\overline{\text { larger }}$ prototypes.

Weaknesses from Design/Constructional/Preparation Methods. Are there inherent limitations in the overall design and preparation that will limit obtaining $10^{5}$ to $10^{7}$ cycles, result in mechanical damage, cause corrosion, or preclude scaleability?

Durability. Does a non-replaceable EC window have a projected 1 ifetime of 15 to 25 years (or 5 years for retrofitted "polymeric" EC devices) based on accelerated testing? How many color/bleach cycles can be anticipated for the required transmittance changes? What degradation in performance is allowable versus years of use?. Does diagnostic evaluation made during real time and accelerated testing confirm that the same degradation mechanisms are occurring in each testing mode? If not, on what basis are the lifetime predictions being made?

Systems Analysis. Has a systems analysis methodology been applied to each candidate EC device to substantiate the ranking for potential success? If not, what research is needed to permit systems analysis ranking to be carried out?

The performance criteria 1 isted in Table 3-1 were obtained from data collected from several researchers for the International Energy Agency Task 10, Subtask $\mathrm{C}$, and by best estimates of the necessary requirements for a building window glazing (Lampert, 1990c). The actual application of the switching device may vary from these idealized values. For example, in automotive applications an EC device is expected to operate at higher temperatures than for a building application. The upper-use temperature might be in excess of $90^{\circ} \mathrm{C}$, but the required 1 ifetime might be only 7 years. For a sunroof application the amount of $\mathrm{UV}$ radiation is higher than for a vertical glazing. The optical values of these data reflect the performance of the entire device. The bleached transmission properties are limited by the optical properties of the transparent conductor and substrate material. Two transparent conductors on glass without the EC layers can lower the maximum solar transmittance to between $72 \%$ and $56 \%$ depending on the material. Because of this, improvements in transparent conductors are also important to the performance of electrochromic devices. Furthermore, for large-scale application, transparent conductors must have very low sheet resistances to overcome resistive power loss and slow switching time. 
Table 3-1. Performance Criteria for EC Windows. (Lampert, 1990c)

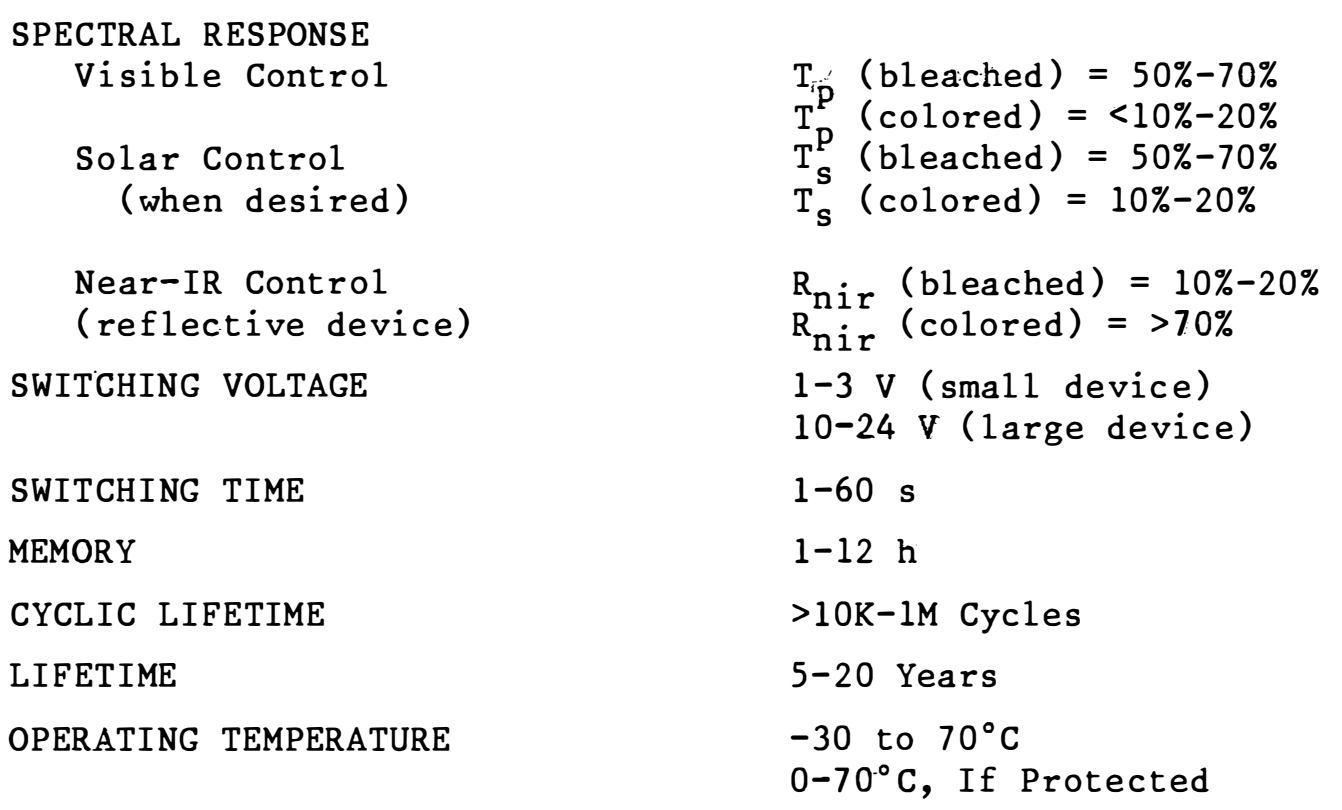




\subsection{PERFORMANCE CRITERIA FOR EC WINDOWS}

As indicated in Section 1.3, we have divided the test methods used in EC window research and development into two categories. In this section, we provide a brief summary of the test methods used for laboratory research. These methods may be used to characterize component film materials, partial assemblies, or a complete window as well as to understand the fundamental physical and chemical processes. This section is summarized with those methods that appear crucial for repeated use to establish the practical suitability and durability of developmental or prototype EC windows.

A common EC device structure is shown in Figure 4-1. To color the EC film, a voltage source is connected between the transparent conductive electrodes (hereafter referred to as ITO for indium tin oxide which is commonly used for this purpose). With a negative voltage on one ITO electrode, electrons are injected from the ITO electrode and protons from the IC layer into the EC film. This continues until the EC layer is converted to the desired color. The coloration process can be stopped at lower color values than the maximum $r$ normal change. Under open-circuit conditions the color remains in the film for some time. Thus, one has a long-term memory device. To bleach the film, the polarity is reversed so that electrons return to the ITO from the EC layer and protons return to the ion storage $\mathrm{CE}$, i.e., electrons and protons leave the same electrode from which they entered the film. Current flows until the

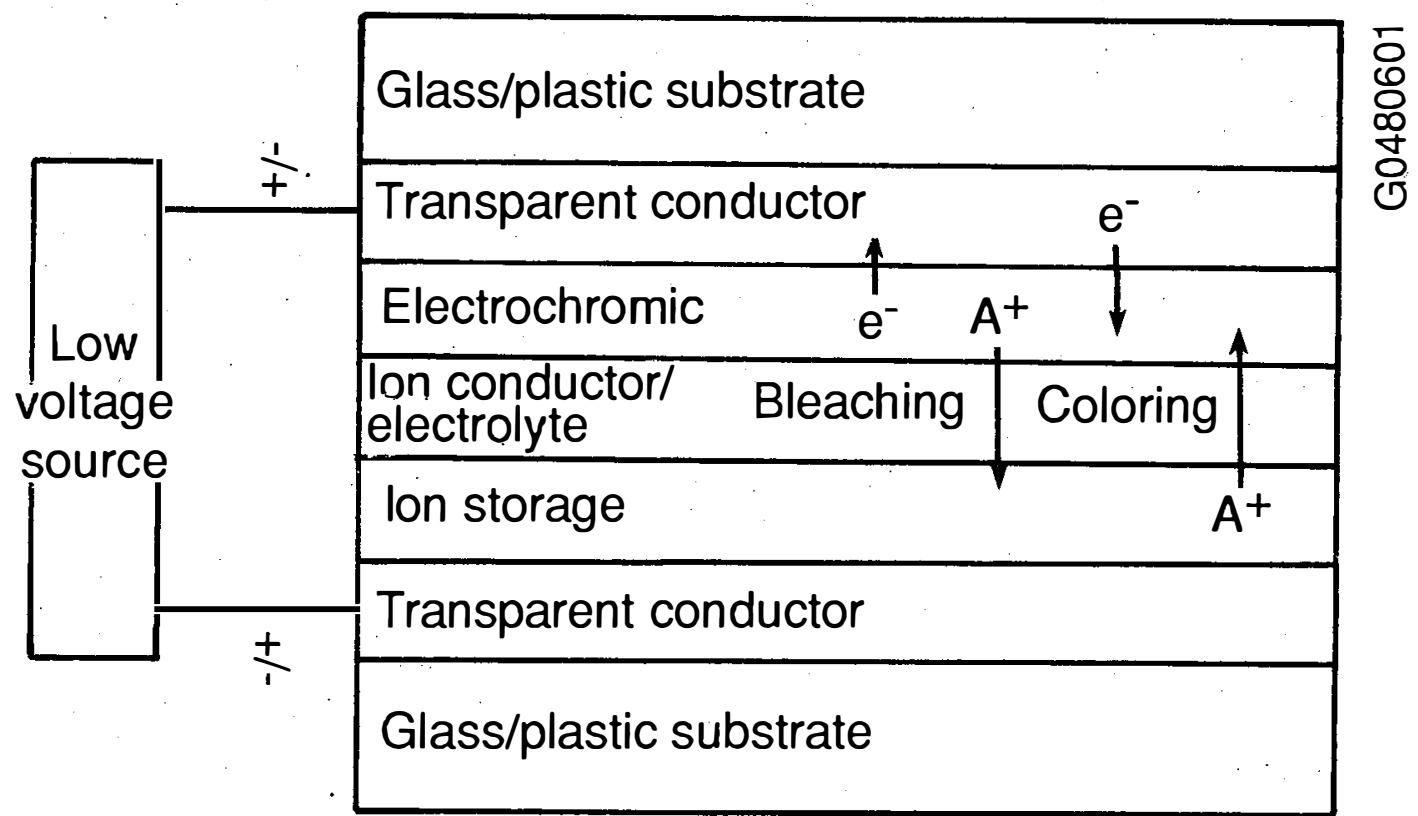

Figure 4-1. Schematic structure of a cathodic EC device 
entire film is restored to its original state of color. It is convenient to think of the color and bleach process as the charging and discharging of a battery. These general physical principles of electrochromism give a rough idea of how the device works but only hint at the complexity of its operation, which requires concepts of solid-state physics, chemistry, and electrochemistry. Each aspect of the device operation has been discussed in detail to show how it affects the overall performance and operation (Faughnan and Crandal1, 1980).

\subsection{Parameters Measured/Used to Establish EC Window Performance}

A number of different measurements or presentations of data are used to evaluate the performance of EC windows. We have listed those that appear most frequently in the literature in Table 4-1. The parameters measured/used are organized in the table in broad categories of optical properties or response, ion insertion or injected charge, open circuit memory, cycle energy, response time, and substrate effects. A review, comparison, and contrast of these "measurements" has recently been made (Lampert, 1990a). As indicated in this review, $T(\lambda), R(\lambda)$, and $A(\lambda)$ versus injected charge are desired rather than the more ambiguous optical density or coloration efficiency.

\subsection{Performance Criteria Expected for EC Windows for Buildings Applications}

The importance of the parameters listed in Table 4-1 for defining the expected performance of an EC window are summarized in this section. More detail is available (Lampert and Granquist, 1990 ).

\subsubsection{Optical Properties}

In many EC materials, the optical properties are due to the presence of a trapped or localized center following ion insertion. In this case, the various optical properties can be interrelated through Smakula's equation (Smakula, 1930), which he introduced for color centers in alkali halides:

$$
\left.\mathrm{Nf} \simeq 8.7 \times 10^{6} \mathrm{nn} /\left[\left(\mathrm{n}^{2}+2\right)^{2}\right]\right\} \alpha_{\max } \mathrm{W}_{1 / 2}
$$

where $\mathrm{N}$ is the number of color centers formed per square centimeter, $\mathrm{n}$ the index of refraction of the film, $\alpha_{\max }$ the absorption coefficient at the band peak in reciprocal centimeters, $W_{1 / 2}$ the full width at half maximum in $e V$, and $f$ the oscillator strength. Thus, the optical properties can be determined by measuring the absorption spectrum.

For example, amorphous $\mathrm{WO}_{3}$ films made by different techniques do not differ qualitatively in their colors or optical absorption spectra. Similarly, the optical properties do not vary significantly for different metal ions electrically inserted. The characteristic blue color of electrochromic $\mathrm{WO}_{3}$ corresponds to an absorption band centered at an energy (wavelength) of $\sim 1 \mathrm{eV}(1242 \mathrm{~nm})$ with a full width at half maximum of $\sim 1.5 \mathrm{eV}(828 \mathrm{~nm})$.

Many different models have been proposed for the nature of the optical transition in electrochromic $\mathrm{WO}_{3}$. Of these, the two models currently most widely held are (1) intervalence charge transitions (Faughnan et al., 1975) and 
Table 4-1. Parameters Related to Performance Criteria Expected for EC Windows-Buildings Applications

OPTICAL PROPERTIES

- Spectral $T(\lambda), R(\lambda)$, and $A(\lambda)$.

- Angular and hemispherical optical measurements

- Integrated solar and photopic transmittance

- Daylighting selectivity

- Fraction of solar transmitted

ION INSERTION, COLOR CENTERS, OR INJECTED CHARGE

- Ion insertion and absorption centers

- Injected charge measurements during coloration and bleaching\# (number of ions or ionic concentration) \#

- Charge capacity measurements, $\mathrm{mC} / \mathrm{cm}^{2}$

- Determination of upper and lower coloration levels

- Coloration efficiency $\left(n_{C E}\right)$ measurement, assumes Beer's Law-cm ${ }^{2} / \mathrm{C}$

- Optical density (OD)

- I-V curves

- Q versus OD

- Potential used to cycle devices and wave form

- Internal emf vs. injected charge (q). An $\varepsilon(q)$ isotherm is a fundamental physical property where $\varepsilon(q)=-e \mu(q)$; e is the electron charge and $\mu(q)$ is the chemical potential of the ion insertion material.

OTHER PROPERTIES

- Ionic Conductivity $\mathrm{In}$ EC, CE, and IC.

- Response time measurement ( $E_{\mathrm{A}} \leqq 0.5 \mathrm{eV}$ for slowest 1on transport)

- Open circuit memory

- Substrate effects eliminated 
(2) free-electron type absorption (Shirmer et al., 1977). In either case, the electrochromism results from the ion-insertion reaction

$$
\mathrm{WO}_{3}+\mathrm{xe}^{-}+\mathrm{xM}^{+}+\mathrm{M}_{\mathrm{x}} \mathrm{WO}_{3}
$$

where $\mathrm{M}^{+}$is an inserted metal ion or a proton. The right side of reaction (2) represents the blue compound formed upon ion insertion. According to the intervalence transition model, electrons injected during coloration are trapped at tungsten sites, whereas $\mathrm{M}^{+}$ions are injected into interstitial positions and retain their charged state. The net result is that during light absorption, an electron on a $\mathrm{W}^{5+}$ site is transferred to an adjacent $\mathrm{W}^{6+}$ site, as in an intervalence transition. This model explains qualitatively the main features of the observed absorption spectrum.

The blue color of electrochromic $\mathrm{WO}_{3}$ observed in both crystalline and amorphous films is due to a broad absorption band that peaks between $0.90 \mathrm{eV}$ $(1380 \mathrm{~nm})$ and $1.46 \mathrm{eV}(851 \mathrm{~nm})$ depending on film properties. Also, its full width at half maximum (FWHM) varies between $1.1 \mathrm{eV}(1129 \mathrm{~nm}$ ) and $2.0 \mathrm{eV}(621 \mathrm{~nm})$. Figure 4-2 shows typical optical-absorption curves.

The optical absorption in amorphous $\mathrm{WO}_{3}$ peaks at approximately $1.46 \mathrm{eV}$ $(851 \mathrm{~nm})$ and the width of the absorption broadens as the density of coloration increases to its maximum, corresponding to $\mathbf{x} \sim 0.5$. The amorphous $\mathrm{WO}_{3}$ curve shown in Figure $4-2$ is for a thin film $(\sim 0.1 \mu \mathrm{m})$ colored to a high optical density and is, therefore, broad.

When amorphous $\mathrm{WO}_{3}$ is crystallized by heating in air, or deposited in a polycrystalline form, its absorption peak shifts to lower energy. This is shown in Figure 4-2 for a film that has been crystallized by heating in air at $500^{\circ} \mathrm{C}$ for 2 min. This shifts its absorption peak to $0.95 \mathrm{eV}(1307 \mathrm{~nm})$. The coloration density is not as great for this film as for the amorphous film and so its absorption is not as broad; e.g., $1.2 \mathrm{eV}(1035 \mathrm{~nm})$ instead of $2.0 \mathrm{eV}$ $(621 \mathrm{~nm})$ for FWHM.

In the same figure, we show the optical absorption arising from a singlecrystal platelet. This crystal was colored by immersing in heated $\mathrm{HCl}$ in the presence of $\mathrm{Zn}$ pellets. Analysis by secondary ion mass spectroscopy shows that it was colored to a density corresponding to $x=0.5$ in a surface layer $0.27 \mu \mathrm{m}$ deep. The depth of this surface layer increases with increased time of immersion in the $\mathrm{HCl}: \mathrm{Zn}$. Interestingly, the properties of the singlecrystal absorption are very similar to the crystallized film and to the amorphous film except for the shift in the peak by approximately $0.5 \mathrm{eV}$ $(2484 \mathrm{~nm})$. The optical properties described above are consistent with equation (1).

Thus, Spectral T, R, and A must be taken over the appropriate wavelength spectrum. For daylighting, this is $390-770 \mathrm{~nm}$; for solar relevance, this is 285-2600 nm. Figure 4-2 illustrates the reason for requiring $T(\lambda), R(\lambda)$, and $A(\lambda)$. $T(\lambda)$ has maxima at different wavelengths for different extents of ion insertion. The fraction of solar radiation transmitted is helpful when assessing the energy input to tine structure, but is a subset of $T(\lambda), R(\lambda)$, and $A(\lambda)$. The angular and hemispherical optical measurements are only needed where specularity of the EC window is important. The integrated and photopic transmittance is retrievable from $T(\lambda)$. 


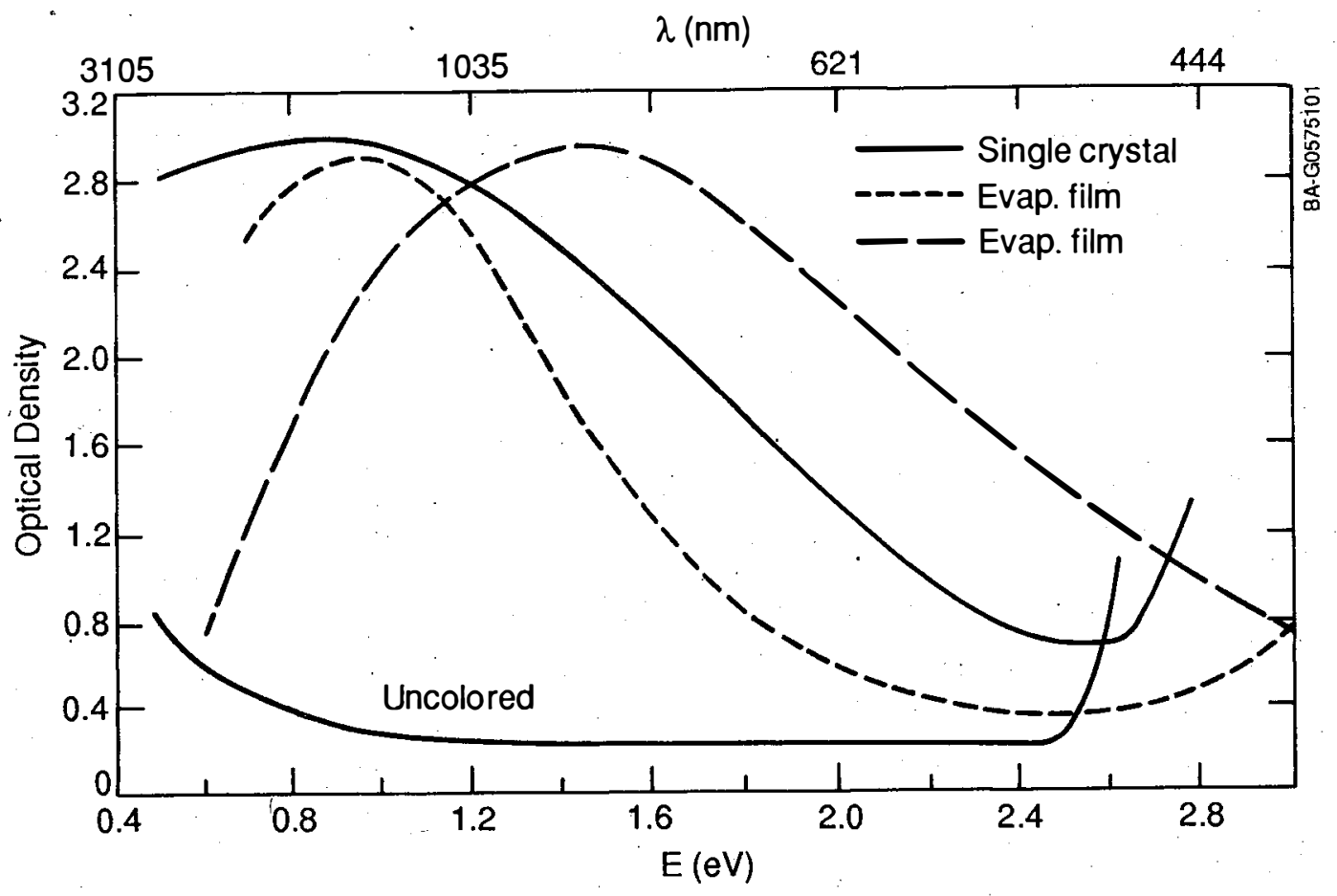

Figure 4-2. Optical absorption in amorphous and crystalline $\mathrm{WO}_{3}$. The $0.25 \mathrm{~mm}$-thick single crystal was colored to a thickness of $0.27 \mu \mathrm{m}$ in $\mathrm{HCl}: \mathrm{Zn}$ for $5 \mathrm{~min}$ at $45^{\circ} \mathrm{C}$ to yield an OD of 3.0 . The $0.5 \mu \mathrm{m}$-thick evaporated film (short dashes) was heat treated in air for 1-2 min at $500^{\circ} \mathrm{C}$ and colored electrolytically to an OD of 1.45 . The $0.1 \mu \mathrm{m}$-thick evaporate film (long dashes) was colored in $\mathrm{HCl}: \mathrm{Zn}$ for $5 \mathrm{~min}$ at $45^{\circ} \mathrm{C}$ to an OD of 0.85. (After Faughnan and Crandal1, 1980).

Optical measurements are necessary to determine the effectiveness of the electrochromism of component films and can be used to.calculate color changes. The wavelength-dependent $T, R$, and $A$ also depend on film thickness(es). A complete multilayer EC window is not a simple result of the optical characteristics of its component layers because of multiple reflection and interference effects, thus, making the calculation of the optical response of a complete device somewhat difficult. Therefore, the wavelength dependence of $T$, $R$, and A are also necessary for an EC device. As summarized elsewhere (Lampert, 1990a), reference standards are required for solar and visible weightings and color coordinate calculations. The recommendations made for reporting film thicknesses, substrate used, specular and diffuse measurements, etc. are needed for comparisons of work from different research groups (Lampert, 1990a).

The following discussion on reflectivity modulation and measurements is based on a recent communication and results (Goldner et al., 1990).

"Ideally, to avoid unnecessary absorption, which can lead to long term degradation as well as thermal radiation Eransfer inefficiencies, the EC layer in an electrochromic window should have a spectral reflectivity which is a step-function. Below a critical wavelength, $\lambda$, the reflectance should be zero ( $100 \%$ transmissivity), and above $\lambda_{p}$ the reflectance should be $100 \%$ (zero 
transmissivity) and $\lambda$ should be controllable. An ideal free electron (Drude) solid with no damping (no electron scattering) would exhibit the desired reflectivity step function, with $\lambda_{p}$ corresponding to the plasma wavelength. That is, $\lambda_{p}=\left(2 \mathrm{nc} / \omega_{\mathrm{p}}\right)$, $\left(c=\right.$ vacuum velocity of 1 ight $\omega_{p}{ }^{2}=\left(\left[n_{e}\right] q^{2} / m^{*} \varepsilon_{0}\right),\left[p_{e}\right]=$ denspty of free electrons, $q$ = electronic charge, $m *$ = electron effective mass, $\varepsilon_{0}=$ vacuum dielectric constant). Therefore, for the ideal Drude solid, a step-like spectrally selective reflectance modulation can be accomplished by modulating the free electron density. In any real film, however, there is some free electron scattering. This is introduced into the Drude model by the use of the damping or energy loss parameter, $E_{\Gamma}$, which largely determines the shape and height of the reflectivity step. Also, for films, as $E_{\Gamma}$ is reduced, the required film thickness to attain a desired reflectance step is likewise reduced. This can strongly affect the economics as well as the physical properties of electrochromic windows. In particular, reduced thickness translates into diminished materials and fabrication costs, and shorter switching time; and finally, redcued $E_{\Gamma}$ and thickness translate together into significantly reduced heating from optical absorption (recall that optical absorption is a function of the product of the thickness and absorption coefficient). Therefore, being able to identify the causes of $E_{\Gamma}$, and removing them, is both an interesting scientific challenge as well as of technological importance."

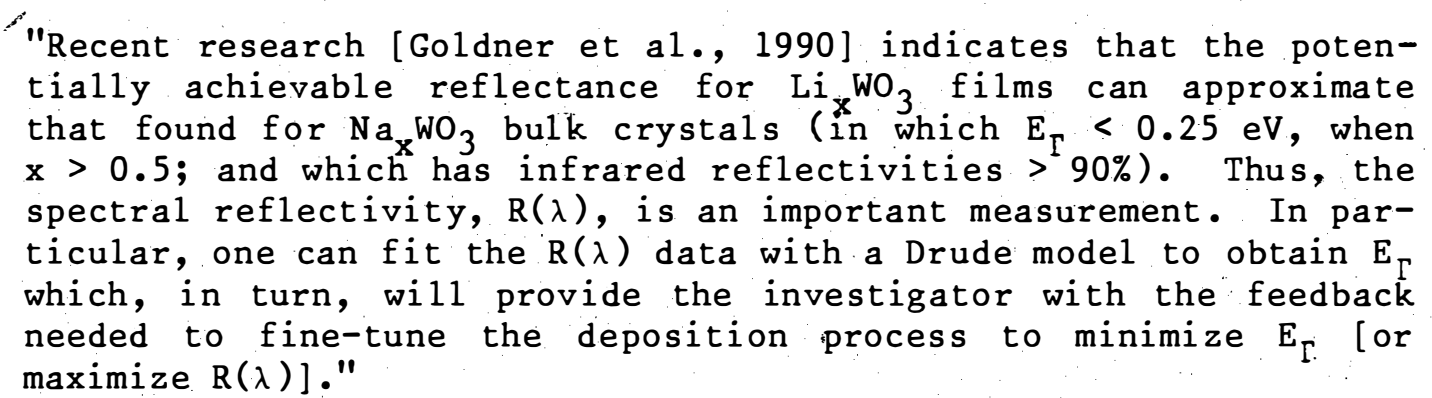

\subsubsection{Ion Insertion, Color Centers, or Injected Charge}

A number of parameters or terms, some fundamental and some derived, are all related to the optical absorption that causes the decrease in transmittance in the visible spectrum when a voltage is applied to an EC window. Charge neutrality is conserved by transport of ions and electrons. The interrelationships of the absorption and transmittance have been discussed (Beni and Shay, 1982; Lampert, 1990c).

The voltage required to drive an EC device is typical of that for a galvanic cell ( $1 \mathrm{~V}$ ) and the optical density (OD) ( $\log _{10}$ of induced absorption) is proportional to the injected ion concentration and to the oscillator strength of the optical transition. It is easy to show that if the ion with changed valency in an electrochromic material has the same or nearly the same surroundings as the unperturbed ion, then strong optical charge transfer absorption bands necessarily exist (Robin and Day, 1967). Thus, in solids in which a valency change is easy to perform, a strong absorption is almost always present. 
An important property of an ion-insertion material is its internal electromotive force (emf). To define it, the capacity of the ion-insertion material must be considered first. This is the maximum number $N_{\max }$ of ions that can be inserted in a unit volume. When $\mathbf{N}$ ions per unit volume are inserted in the material, the relative ion-occupancy $q=\mathrm{N} / \mathrm{N}$ max determines the chemical potential $\mu(q)$ of an ion in the ion-insertion material. In turn, the chemical potential is related to the internal emf $\varepsilon(q)$, which varies with the temperature; at a given temperature the function $\varepsilon(q)$ is usually referred to as an isotherm of the ion-insertion material. Isotherms of electrochromics are measurable and have been studied extensively (Crandall et al., 1976; Crandall and Faughnan, 1977; Hitchman, 1977; Beni and Shay, 1980; Beni et al., 1980). The $\varepsilon(q)$ isotherm is the most fundamental property for characterizing the ioninsertion material (see, for example, Crandall and Faughnan, 1976).

The symmetric cell shown in Figure 2-1 depicts electronic conductors in shaded layers 1 and 5; layers 2 and 4 are ion-insertion mixed conductors, and layer 3 is the electrolyte. For simplicity, let layers 1 and 5 and layers 2 and 4 be identical. Let us assume also that the relative ion occupancies $q_{4}$ of layer 4 and $q_{2}$ of layer 2 are such that $q_{2}+q_{4}=1$. The potential difference between layers 1 and 5 is $\Delta \varepsilon=e\left[\mu\left(q_{4}-\mu\left(q_{2}\right)\right]\right.$. Thus, if layers 1 and 5 are externally connected and if $q_{2} \neq q_{4}$, ions will be transferred between layers 4 and 2 across the electrolyte 3 until $\mathrm{q}_{2}=\mathrm{q}_{4}=1 / 2$ and $\Delta \varepsilon=0$. Such a cell is in thermodynamic equilibrium and can be displaced from equilibrium by applying an external voltage between layers 1 and 5 . If, by application of the appropriate voltage, a configuration $q_{2}, q_{4}\left(q_{2}+q_{4}=1\right)$ is obtained, this configuration persists after opening the external circuit since charge cannot be transferred unless layers 1 and 5 are connected. This property of the cell is referred to as open-circuit memory (OCM), which is time dependent because some EC devices are self-discharging.

\subsubsection{Open Circuit Memory and Calculation of Cycle Energy}

The time dependence of the OCM can be used as a measure of the cycle energy consumed in the use of EC windows. In practice, a short OCM will be indicative of increased power consumption of the device. In laboratory studies, the cyclic energy input into an EC window makes such a minor contribution to the life cycle cost that it need not be determined unless the OCM becomes extremely short for some unusual reasons.

\subsubsection{Response Time}

The EC response times, i.e, the times required for coloration and bleaching, are determined primarily by the mobility of the injected ions at the filmelectrolyte interface (and in the film itself), and the internal emf due to ion insertion. There is a trade-off between OCM and response time, where a long OCM (low power consumption) also means a long response time (slow switching speed) (Benson, 1989). For $\mathrm{WO}_{3}$ it has been established (Faughnan et al., 1975) that the coloring and bleaching speeds are governed by different effects. Coloration is controlled by the kinetics of ion. injection at the $\mathrm{WO}_{3}$-electrolyte interface, whereas the speed is determined by space-charge limited transport.. The asymmetry between the processes of charge injection and extraction is due to the internal emf associated with the presence of the injected ions. During coloration, the internal emf builds up to oppose the applied cathodic potential that drives cations into $\mathrm{WO}_{3} \cdot$ However, during 
bleaching the internal emf decreases and thus facilitates the extraction of positively charged ions from the electrochromic film. Crandall and Faughnan (1975, 1976) and Faughnan et al (1975) have developed a theory for the dynamics of coloration and bleaching in $\mathrm{WO}_{3}$. They also conclude that for good electrochromic performance in a solid at room temperature, the activation energy for the slowest carrier must be $10 \mathrm{w}, 0.4 \mathrm{eV}$ or less. Since the slowest carrier is usually the ionic carrier, this places the search for good EC materials within the class of fast-ion (or superionic) conductors.

Amorphous films of tungsten or molybdenum trioxide are good EC device materials for two reasons. Injection properties of ions and electrons and high ion mobilities result in a strong optical absorption in the visible. A high ion mobility is required because coloration entails injection of positive ions, and bleaching entails extraction of positive ions. Ions such as $\mathrm{Li}^{+}$, $\mathrm{Na}^{+}$, and $\mathrm{Ag}^{+}$have been used in $\mathrm{WO}_{3}$ EC devices in place of $\mathrm{H}^{+}$, however, with some sacrifice in response time and coloration efficiency.

There are a number of variables involved that cause the response time to depend on the device size. Thus, the response time varies with device size, sheet resistivity, applied voltage, I-V characteristics, and thickness. When ITO is used, electron transport and resistive losses limit the response time for sizes exceeding 10 to $100 \mathrm{~cm}^{2}$ (Lampert and Granqvist, 1990).

A number of test methods are used for studying electrochromic devices, and all of the methods known are not standardized. The type of methods used include cyclic voltammetry and square wave cycling. Cyclic voltammetry is a measure of the cyclic current and voltage response of the device. A triangle potential is used as the driving potential (usually under $+/-2 \mathrm{~V}$ ) and a reference electrode is used to correlate potentials to known electrochemical processes. Cyclic voltammetry is very good for determining chemical changes in the electrode as it cycles. In general, a dc voltage is used to drive actual devices. Square wave cycling is used to simulate an accelerated cyclic dc potential response. However, because electrochromism is a current-controlled phenomenon, current sources with controlled voltage have also been used for testing.

Examples of idealized responses for cathodic and anodic type electrochromic devices are shown in Figure 4-3. A measure of performance is CE expressed as $\mathrm{cm}^{2} / \mathrm{C}$. To obtain this value, the change in OD with the total injected/ejected charge as a function of unit area must be known. This measurement does not yield the injected charge/unit volume. Film density and thickness measurements would allow the needed quantity to be calculated from the usually presented values of $\mathrm{C} / \mathrm{cm}^{2}$. However, even charge/unit volume does not address the issue of possible concentration gradients in injected charge in-depth from the electrode/electrolyte interface. The latter information can be obtained by integration of voltammetry data or by the use of a coulomb meter. Information on the amount of charge required for coloration compared to bleaching will also give the efficiency of each half cycle. The change in surface density of charge, $\mathrm{mc} / \mathrm{cm}^{2}$, (many authors also refer to this quantity as charge, charge capacity, or charge per unit area) is monitored during cyclic testing. In some cases the coloration and the bleaching cycle require different amounts of charge to give the same change in optical density. The rates at which a device colors and bleaches are usually different, as described earlier. Coloration efficiency should be used with reservation on single component films, but it is good for comparison purposes. It does not necessarily predict the response of a complete device unless measured for a complete device. 

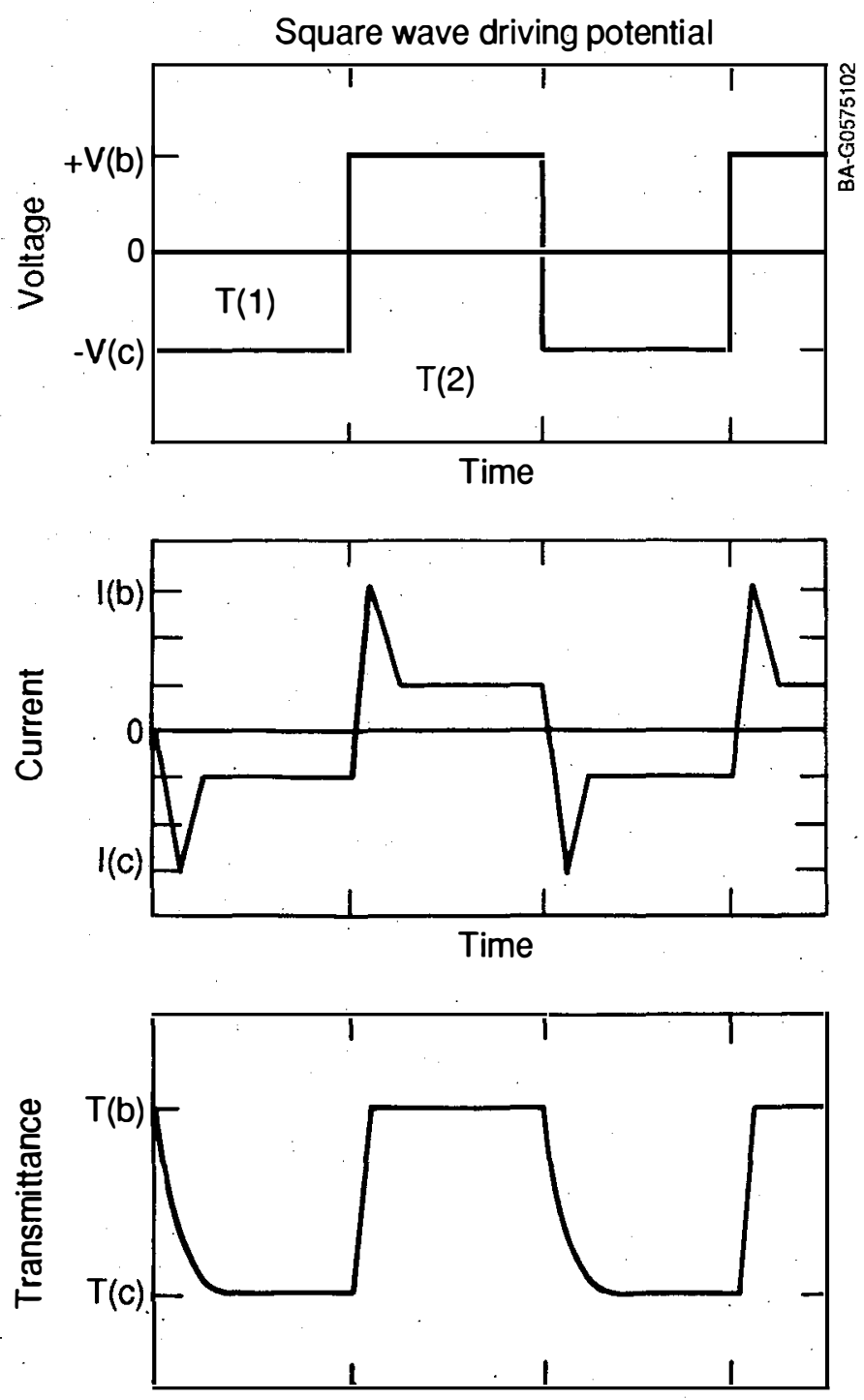

Time

Figure 4-3. Response of an idealized electrochromic tungsten oxide switching device. The driving potential and current with resulting transmittance response are shown (after Lampert, 1990c)

The change in optical density $(\triangle O D(\lambda))$ can be obtained from the relationship between injected charge $(Q)$ and the coloration efficiency: $\Delta O D(\lambda)=Q / \eta_{C E}(\lambda)$. Also, optical density can be obtained by $\Delta O D(\lambda)=\log \left(T_{p}(\lambda) / T_{c}(\lambda)\right)$, where $\mathrm{T}_{\mathrm{b}}(\lambda)$ is the bleached transmittance and $\mathrm{T}_{c}(\lambda)$ is the colored transmittance.

For transparent devices, the absolute values of $O D$ must be given, defined as: $\quad O D=\log \left(\mathrm{T}_{0}(\lambda) / \mathrm{T}_{x}(\lambda)\right.$, where $\mathrm{T}_{0}(\lambda)$ is the incident or reference transmittance and $T_{x}(\lambda)$ is the measured transmittance value of the device.

Because we are interested in the modification of the photopic and solar spectra, both spectral and integrated data should be reported. 
In summary, the electrochemical measurements on component films and/or complete EC windows are used:

- to establish reversibility of the ion insertion reactions

- to measure the kinetics of ion insertion (diffusivity)

- to establish the voltage range over which films are stable

- to establish the voltage range over which component films are compatible (free of irreversible reactions) with each other

- to detect incipient signs of degradation and thus serve as an abbreviated lifetime predictor.

The electrochemical measurements on component films and/or complete EC windows should be measured over the application temperature range $\left(\mathrm{e.g.}, 0\right.$ to $70^{\circ} \mathrm{C}$ for an indoor EC window).

\subsubsection{Substrate and Other Effects}

It is well known that the structure/morphology/properties relationships of deposited films/coatings may be altered because of substrate effects or influences. For the purposes of this report, we assume that any adverse influences at the $\mathrm{TC} /$ substrate interface are eliminated by the choice of the normally used ITO and substrate material, as well as for possible problems arising from deposition of the other layers in the device. Substrate effects are not restricted to the obvious structure/morphology/properties relationships at the $\mathrm{TC} /$ substrate interfaces shown in Figure 4-1. The ITO in turn serves as a "substrate" for the next layer, etc. The optical properties of the device; ion transport in the EC, IC, and CE materials; and stability of the interfaces from interdiffusion may all be affected in a multilayer stack. Again, we assume these potential problems are eliminated by the choices of the layer materials and deposition processes following laboratory research investigations.

\subsection{Laboratory Performance Evaluation}

A number of questions must be answered about measurements and standardized procedures made for laboratory performance evaluation.

(a) How do large-area versus small-area devices affect evaluation?

(b) How are solar and visible transmittance measured? Are integrated values used?

(c) How is the amount of injected charge measured during coloration and bleaching? Is it given by $\mathrm{C} / \mathrm{cm}^{2}, \mathrm{C} / \mu \mathrm{m}-\mathrm{cm}^{2}$, or some other unit? Does it involve integration of the current and control of the voltage with a reference electrode when possible, and what is the power dependence (limitation of current and voltage)? Finally, is the amount of injected charge reversible during cycling?

(d) What type of potential is applied (form and magnitude)? At what rate? During what period? Are rest periods used? How many current-voltage (I-V) cycles should be used?

(e) What is the effect of using different types of potentials? 
(f) How is charge capacity $\left(\mathrm{mC} / \mathrm{cm}^{2}\right)$ measured?

( $g$ ) How is coloration efficiency $\left(\mathrm{cm}^{2} / \mathrm{c}\right)$ measured?. Should it be an integrated value? Is energy/unit area divided by the optical density a suitable expression? What wavelength is used?

(h) How should ionic conductivity be measured?

(i) What is the crystalline and/or amorphous content of the material(s)?

(j) \# How is device response time measured, and under what conditions? Is the coloration time adequate for reducing the initial transmittance $T_{0}$ (where $\mathrm{T}_{0}>50 \%$ for an EC window) to $0.3 \mathrm{~T}_{0}$ ? Is a bleaching time for increasing the transmittance up to $0.9 \mathrm{~T}$ o adequate? Are both needed?

(k) How is cycle energy calculated? (use open circuit)

(1) Should IR spectra be measured if water incorporation occurs?

(m) What is the depth distribution of injected charge? How does this vary with cycle time and applied voltage?

(n) What is the morphology of the EC and CE films? This information is essential to consider the paths the injected charge will most likely follow.

Efforts to answer some of the above questions are being made (Lampert, 1990). These answers are very important for use in durability testing.

\subsection{Ranking of the Most Important Parameters from Table 4-1.}

As a summary of Section 4, the most important parameters/measurements 1 isted in Table 4-1 and data needed to evaluate the performance of EC windows are as follows:

(a) $T(\lambda)$, and $R(\lambda)$, and $A(\lambda)$ even when an EC window is primarily reflective or absorptive

(b) The injected charge/unit volume or charge capacity, and correlated with optical changes in (a)

(c) I-V curves where $\mathrm{V}$ is cycled between the voltages required to provide the colored and bleached states. Degradation of performance will be monitored from the optical measurements in (a). The detailed I-V curves vary for devices of different types, but should be reproducible for a given device type.

(d). The temperature dependence of a response time, where definitions of the color/bleach limits are established.

All of the above measurements should be done simultaneously.

Measurements that are of limited usefulness include coloration efficiency, optical density, and cycle energy consumption. Many of these depend on the application. Isotherms of $\varepsilon(q)$ are fundamental but may not be required to evaluate device performance. 


\subsection{TEST METHODS AND PROCEDURES FOR EVALUATING EC WINDOW STABILITY AND/OR DURABILITY}

\subsection{Introduction to Degradation}

This section deals with test methods and procedures for evaluating the durability of complete EC windows. For the potential of EC windows to be realized, a number of problems must be resolved that deal with degradation in their performance. Some of these effects include residual coloration, loss of dynamic range, and stability of the device during prolonged cyclic use. Performance losses result from imposed degradation parameters and we have chosen to discuss them under the categories of degradation stresses, effects, modes, and mechanisms. Degradation stresses refer to conditions, imposed or natural, that influence or cause a degradation mechanism, effect, or mode. Degradation stresses include UV, humidity, temperature, air, pollutants, thermal shock, cyclic temperature, and cyclic charge injection and bleaching. Degradation effects refer to observed changes that occur during EC window use and that adversely influence the performance of the device, but where the causes (at a molecular level) are not clearly established. Degradation effects include gas generation in some devices, humidity effects, internal water formation, secondary reactions, photoreactions, quenching (fading of color), volume changes, and temperature (dependent) effects. Degradation modes refer to performance losses that result from imposed parametric variations on an EC window and that may be related to a degradation mechanism or an effect. Degradation modes can result from thermal shock, prolonged non-use, constant elevated temperatures, and various cyclic changes. Degradation mechanisms deal specifically with not only an established cause for the loss in performance, but also where the cause can be related to some physical or chemical process at a molecular level. Established degradation mechanisms include film dissolution, corrosion, transparent conductor etching, and hydrogen embrittlement. Some performance losses from degradation are specific to particular EC window materials, as will be evident below.

Performance measurements for real-time and accelerated 1 ife testing are then discussed. These include measuring the transmittance and reflectiance (wavelength dependence) of an EC window in the colored and bleached states, the atomic percent of injected charge, and the time dependence of the change in percent transmittance during coloring and bleaching. The proposed methods and procedures are summarized for real-time and accelerated life testing.

\subsubsection{Degradation Stresses}

Degradation stresses that can be imposed on EC windows or are part of realtime use include exposure to UV, humidity, air, pollutants, temperature, cyclic temperature, thermal shock (cloud cover), cyclic charge injection and bleaching (cyclic I-V input), dust, sand, and dirt. We shall eliminate the latter three for the remainder of this report, but they may be important in actual applications. Sand can cause abrasion of windows, altering its specularity. Dirt and dust may adhere to the glass surfaces, causing scattering and a general reduction in available solar transmittance. The stresses may be imposed during real-time testing, by using accelerated test procedures such as exposure in Weather-Ometer or. QUV test facilities (see Section 5.4), or under static conditions (shelf storage). 
Furthermore, the range of values for the stresses imposed must be chosen to correspond to the variation expected at various use locations. For example, identical silvered polymers being studied for solar reflector applications have been found to degrade in the climates of Arizona (hot, dry) and Florida (hot, wet) but do not degrade in Colorado and Minnesota climates, where the extremes in humidity and temperature are not as great (Jorgensen and Schissel, $1989)$.

\subsubsection{Degradation Modes}

Degradation modes can result from thermal shock (abrupt $\Delta T$ because of cloud cover), prolonged shut down (storage or nonuse), an elevated stagnation temperature, cyclic temperature during use, and cyclic changes in charge capacity, electrochemical instability, and optical properties.\#

The cyclic degradation mode can be illustrated by work done at $\mathrm{RCA}$ on a-WO 3 display devices. The device lifetime is shortened as larger coloration changes are imposed, as shown in Figure 5-1. Furthermore, the degree of degradation is very dependent on the electrolyte type and operating conditions. If a device is to last $10^{6}$ cycles (from the RCA work), then its contrast ratio must be within the range of $2: 1$ to $4: 1$. The contrast ratio is defined in the RCA study as the ratio of reflectances compared to a white background as: $\quad C R(w)=R_{b}(w) / R_{c}(w)$, where $R_{b}(w)$ is the reflectance in the bleached state and $R_{c}(w)$ is the reflectance in the colored state. Work on liquid electrolyte devices containing large amounts of water has suggested that cyclic degradation is an extension of the dissolution. process or voltage enhanced corrosion. In protonic devices that have been cycled for many thousands of cycles and disassembled, the $\mathrm{a}^{-\mathrm{WO}_{3}} \mathrm{film}$ has been found to be granular and is less adherent to the substrate. It is suspected that the film has suffered mechanically from hydrogen embrittlement. The most obvious change during cycling is the gradual reduction of charge per unit area during bleaching and coloration of the film. This results in a decline of the change in the optical density of the film.

In so-called aprotic systems, a- $\mathrm{WO}_{3}$ corrosion is slowed by the processes of low ionizability of large organic molecules and inhibited tungsten ion formation. After 10,000 cycles of coloration and bleaching a-WO 3 electrodes cycled in $\mathrm{LiClO}_{4}$-propylene carbonate (PC), a decrease in injected charge density is noted. The charge density began at $10 \mathrm{mC} / \mathrm{cm}^{2}$ and dropped to $6 \mathrm{mC} / \mathrm{cm}^{2}$ after $1 \mathrm{M}$ cycles. An example of this is shown in. Figure 5-2. Only an electrochemical emf change was noted in the film. After cycling, lithium ions were found bound into the film structure and were judged responsible for the emf shift but not active in coloration. After cycling, the film in the bleached state becomes more ion conductive as the result of 1 ithium incorporation (Nagai et al., 1984, 1986a, 1986b; Kamimori et al., 1987). There appear to be two active sites for lithium ions; one for coloration: $a-\mathrm{WO}_{3}+\mathrm{xLi}^{+}+$ $\mathrm{xe}^{-}<-->\mathrm{a}-\mathrm{Li}_{\mathrm{X}} \mathrm{WO}_{3}$ and another for ion exchange according to: $\mathrm{W}-\mathrm{O}-\mathrm{H}+\mathrm{Li}^{+}<--$ $>\mathrm{W}-\mathrm{O}-\mathrm{Li}+\mathrm{H}^{+}$. The $\mathrm{O} / \mathrm{W}$ ratio also increased during cycling. This result may mean that the a- $\mathrm{WO}_{3}$ may form a metatungstate structure " $\left(\mathrm{M}_{6}^{+}\left(\mathrm{W}_{12} \mathrm{O}_{39}\right)\right.$ " where $\mathrm{M}=\mathrm{H}$, Li, etc., which can serve as an ion exchange site. A charge decay factor of two has been noted after $100 \mathrm{~h}$ of cycling $\left(9 \times 10^{4}\right.$ cycles $)$ of a $\mathrm{a}-\mathrm{WO}_{3} / \mathrm{LiClO}_{4}-\mathrm{PC} / \mathrm{Li}_{x} \mathrm{WO}_{3}$ device. It was found that by irradiating the cell with UV light while applying a bleaching voltage, the decline in the charge injection level was reduced (Knowles, 1977). 


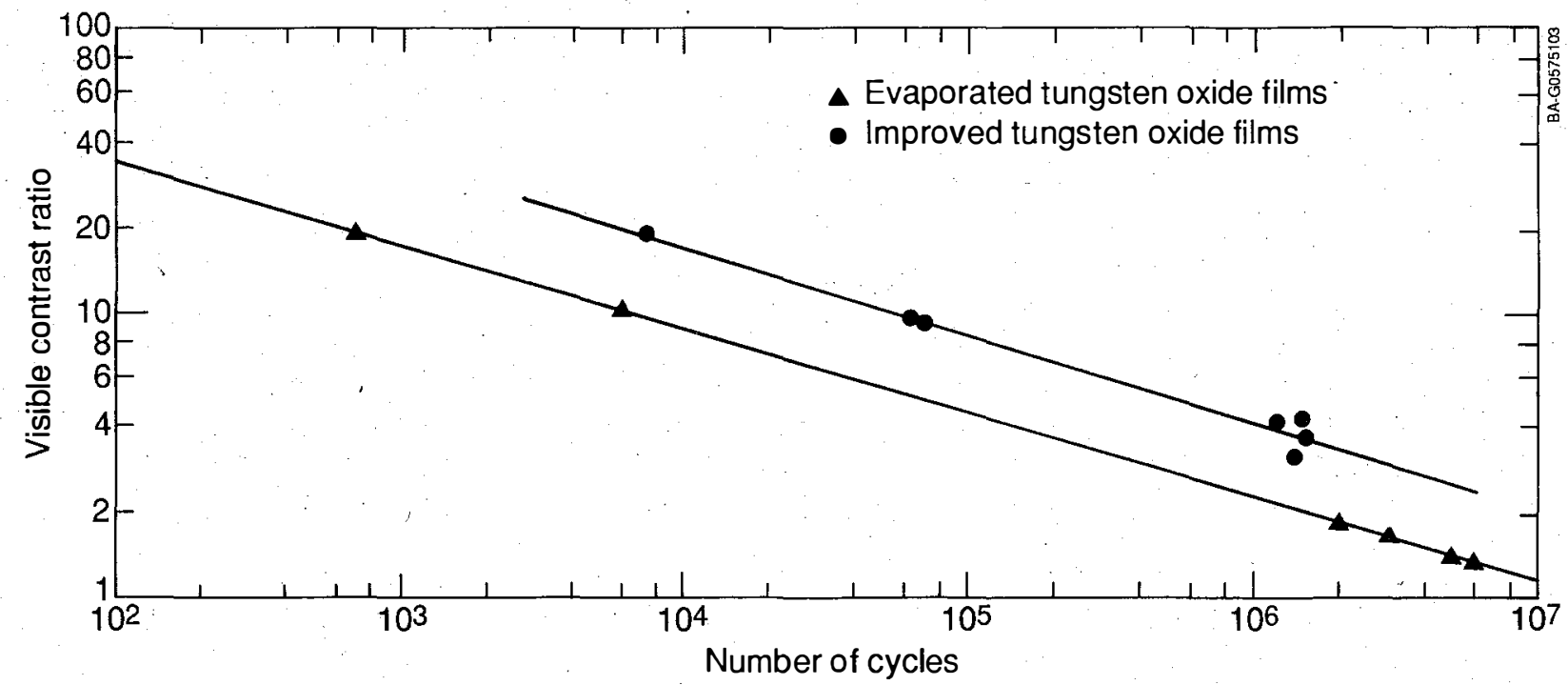

Figure 5-1. Relationship between contrast ratio and 1 ifetime for a tungsten oxide electrochromic device (ITO/a-WO 3 /electrolytel metal). Two device responses are shown: (A) standard vacuum evaporated film and (B) films produced by an improved process (Faughnan and Cranda11, 1980).

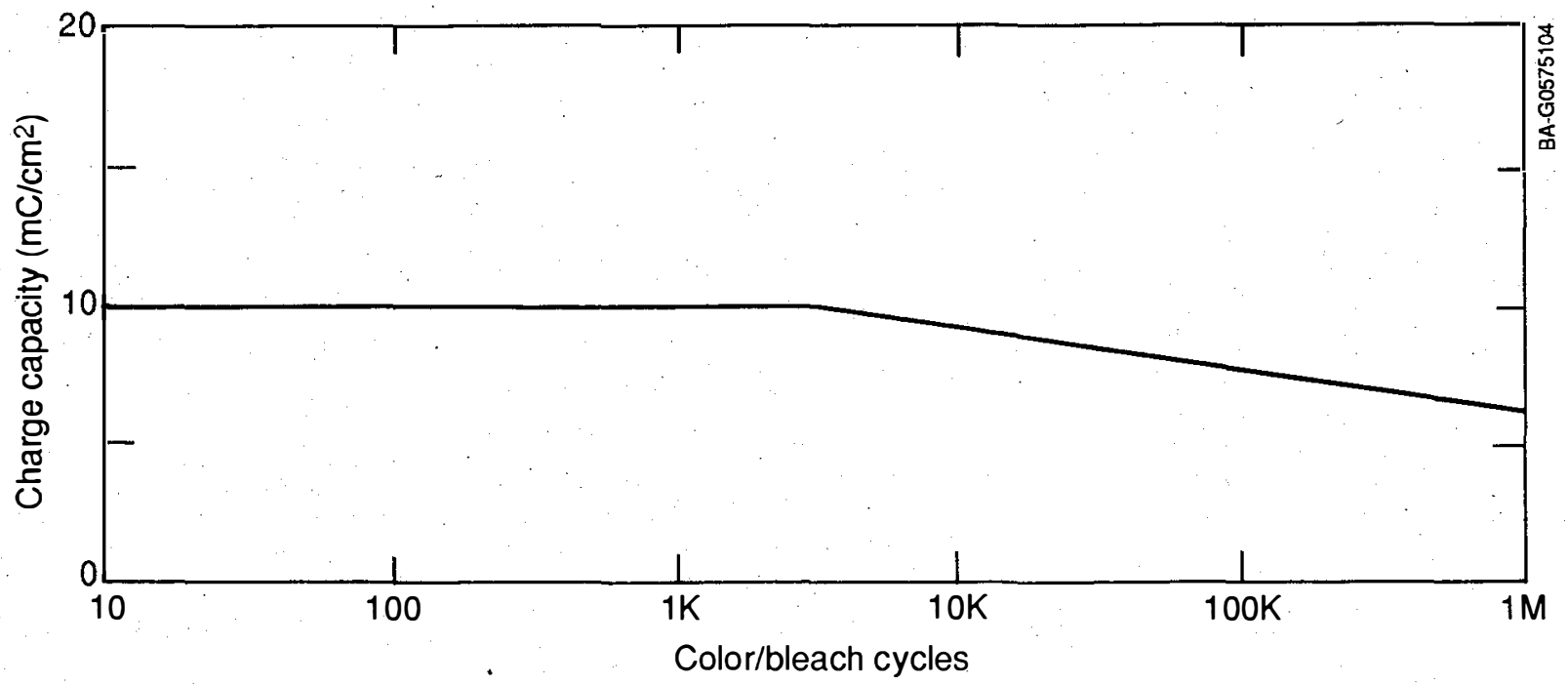

Figure 5-2. Long term cycling of tungsten oxide devices (ITO/a-WO $3 / \mathrm{LiClO}_{4}+$ Redox/ITO). The decline in charge capacity (charge per unit area) and hence optical density can be seen after long cycling. This effect is seen in many device types. (Nagai et al., 1984, 1986a, 1986b, Kamimori et al., 1987). 
Preliminary work on the cycling of sputtered electrochromic $\mathrm{Ni}(\mathrm{OH})_{2}$ has shown only a small change in the transmittance after $10^{4}$ cycles (Svensson and Granqvist, 1987). Work on cathodic electrochemically deposited $\mathrm{Ni}(\mathrm{OH})_{2}$ has shown early residual coloration after cycling (Carpenter et al., 1987). But work on anodically deposited $\mathrm{Ni}(\mathrm{OH})_{2}$ films and devices has shown good stability (Lampert, 1990b; Yu et al., 1987; Pennisi and Lampert, 1988). In the near future, commercial studies on $\mathrm{Ni}(\mathrm{OH})_{2}$ or $\mathrm{NiO}$ will be published that show a stability has been obtained for $>10^{6}$ cycles for Nio solid state devices.

Electrochromic displays using a sputtered iridium oxide/ $\mathrm{SnO}_{2} / g$ lass anode in a $0.5 \mathrm{M} \mathrm{H}_{2} \mathrm{SO}_{4}$ solution have been subjected to cyclic 1 ifetime testing at 22 and $73^{\circ} \mathrm{C}$ (Dautremont-Smith et al., 1980). At $22^{\circ} \mathrm{C}, 2 \times 10^{7}$ coloring bleaching cycles were obtained without a perceived change in contrast. The fully colored or bleached state was reached during about half of the cycles. A decrease in the injected charge $(\Delta Q)$ and $\triangle O D$ of about $3 \%$ was recorded at $22^{\circ} \mathrm{C}$ while a $5 \%$ decrease in these quantities occurred during $2 \times 10^{5}$ cycles.

\subsubsection{Degradation Effects}

Degradation effects include gas generation in some devices, humidity effects, internal water formation, secondary reactions, photoreactions, quenching, volume changes (density changes), structural changes, diffusion of "fixed" atoms (e.g.; W, 0), trapping of mobile ions, and temperature dependence. All of these effects may reduce the performance of EC devices. As explained below, most of these effects are device-specific except perhaps the temperature dependence.

At elevated temperatures, it is well known that chemical reactions are accelerated, or become fast enough to result in measurable effects. The acceleration factor can be calculated from the Arrhenius relationship if both the preexponential and activation energy are known. Use of this relationship requires it to be valid (for the same mechanism) over the temperature range of interest. For the favorable reactions, prolonged exposure to high temperatures will accelerate the degradative effects on the materials. Intuitively, prolonged exposures of the materials to $80^{\circ} \mathrm{C}$ in an all-solid state EC windows should not result in degradative reactions, even for solid polymeric electrolytes if they are properly chosen (e.g., UV and $T$ stable). However, the synergism of elevated $\mathrm{T}$, humidity, $\mathrm{UV}$, and pollutants may result in undesired reactions that limit the 1 ifetime of an EC window. The strongest-synergism noted for existing devices is between $U V$ and T. Thus, elevated temperatures, separately and as a combination of imposed parameters, must be used in a testing program for EC windows.

Gas Generation. Internal gas generation is a very serious device degradation and failure effect. For a- $\mathrm{WO}_{3}$ devices injected with $\mathrm{H}^{+}$, there is a danger of generating $\mathrm{H}_{2}$ gas if the voltage across the device is too high. Also, if the a-WO $\mathrm{Wilm}_{3}$ is colored to $\mathrm{H}_{\mathrm{x}} \mathrm{WO}_{3}$ beyond $\mathrm{x} \simeq 0.28$, then an electrode-electrolyte interface reaction can occur causing dissolution of $\mathrm{H}_{\mathrm{x}} \mathrm{WO}_{3}$ and formation of $\mathrm{H}_{2}$ gas (Faughnan and Crandal1, 1980). Gas is also generated in the $\mathrm{LiClO}_{4}+\mathrm{PC}$ devices (Kase et al., 1986), which fits a pattern of problems encountered in 1 iquid-based devices.

In ITO/a-WO $/$ IC/Au devices, water in the device apparently dissociates at the Au interface during coloration. During bleaching, gas bubbles are observed at 
the $\mathrm{Au}$ interface during application of a $-1 \mathrm{~V}$ potential (Yoshimura et al., 1982). For electrochromic $\mathrm{TiO}_{2}$ the coloration peak occurs after the oxygen evolution potential. This makes $\mathrm{TiO}_{2}$ impractical for use with water-based electrolytes because of gas generation.

Water and Humidity Dependence. Another important effect occurs in ITO/ a-WO 3 /IC/Au devices. These devices have been reported to be very dependent upon ambient humidity. The mass changes that occur during coloration and bleaching correspond to adsorption and desorption of water in the cell and its surroundings. Mass spectrometer measurements have shown that oxygen leaves the cell during coloration and hydrogen leaves the cell during bleaching. Coloration does not occur until a threshold voltage, which corresponds to the electrolysis of water, is reached across the insulating layer. This electric charge disassociates the water in the insulating layer thereby providing the necessary protons for coloration (Hughes and Lloyd, 1977; Hajimoto et al., 1979; Stocker et al., 1978).

The coloration and bleaching process was studied in an $\mathrm{ITO} / \mathrm{a}-\mathrm{WO}_{3} / \mathrm{a}-\mathrm{SiO} \mathrm{S}_{2} / \mathrm{Au}$ device (Lusis et al., 1982, 1984). According to these authors, the gold interface serves as a surface for catalytic dissociation of water. When the device voltage exceeds $1.3 \mathrm{~V}$, a hydroxide layer is formed on the gold surface following: $\mathrm{Au}+3 \mathrm{OH}^{-}-->\mathrm{Au}(\mathrm{OH})_{3}+3 \mathrm{e}^{-}$. At this stage coloration takes place in the $\mathrm{a}-\mathrm{WO}_{3}$ layer. Above $1.6 \mathrm{~V}$ the threshold for oxygen discharge is reached. On the negative current cycle, the reduction of gold hydroxide occurs at $0.8 \mathrm{~V}$ and bleaching begins; water is reformed at $-0.1 \mathrm{~V}$. Final bleaching of the $\mathrm{a}-\mathrm{WO}_{3} \mathrm{film}$ is observed at $-0.4 \mathrm{~V}$. At $-3 \mathrm{~V}$ oxygen evolution occurs. The presence of water in this device is important to its operation and the gold layer serves as the catalytic surface.

Secondary Reactions. The organic viologen system has always been attractive for switching devices because its absorption spectrum can be adjusted at any visible wavelength, it has high charge efficiency $\left(2.5\right.$ times better than $\mathrm{WO}_{3}$ ), and switches fast. The problem with the viologens is that they show unexpected secondary irreversible reactions with use (Masumi et al., 1982). Because these reactions are seen in conjunction with liquid electrolytes, there is a possibility of suppression with solid electrolytes (Hari and Tani, 1983).

Photoreactions. It is known that $\mathrm{a}^{-\mathrm{WO}_{3}}$ is photochromic when exposed to UV radiation (Gissler and Memming, 1977; Fleisch and Mains, 1982). The photocurrent rises dramatically for wavelengths below $400 \mathrm{~nm}$. For annealed films the photocurrent rises between 400 and $480 \mathrm{~nm}$. In a- $\mathrm{WO}_{3}, \mathrm{~W}^{+6}$ is converted to $\mathrm{W}^{+5}$ under irradiation of $\mathrm{UV}$ light at $253 \mathrm{~nm}$ in vacuum at $22^{\circ} \mathrm{C}$. An electrochromic device based on a- $\mathrm{WO}_{3}$ will have its bleaching and coloration kinetics retarded by the effect of photochromic transitions to $\mathrm{W}^{+5}$. This may be a reason why indoor and outdoor tests give different rate kinetics (Nagai et al., 1986b). After $100 \mathrm{~h}$ of UV irradiation in a Weather-Ometer at $63^{\circ} \mathrm{C}$, the injected charge dropped from 13 to $8 \mathrm{mC} / \mathrm{cm}^{2}$. Since the measured outdoor $\mathrm{UV}-\mathrm{flux}$ is negligible below $285 \mathrm{~nm}$ (Webb et al., 1984), other influences may cause the observed kinetic differences, i.e., $253 \mathrm{~nm}$ is imposing an energy that is greater than encountered in reality.

Photochromism can also be used to regenerate aged a-WO 3 devices. After long cycling the EC layer or electrolyte contains trapped charge, which causes the 
charge injection levels to fall, and an emf shift is noted of $-170 \mathrm{mV}$. A contrast ratio of 4:1 was seen before cycling. The peak current density was $4 \mathrm{~mA} / \mathrm{cm}^{2}$ bleached and $-5 \mathrm{~mA} / \mathrm{cm}^{2}$ colored. After $100 \mathrm{~h}\left(9 \times 10^{4}\right.$ cycles $)$, the peak current was $1 \mathrm{~mA} / \mathrm{cm}^{2}$ bleached and $-4 \mathrm{~mA} / \mathrm{cm}^{2}$ colored. After UV regeneration the bleaching currents became $2 \mathrm{~mA} / \mathrm{cm}^{2}$ and $-5 \mathrm{~mA} / \mathrm{cm}^{2}$ colored. By irradiation and biasing the device in the bleached state, the energy of incident UV is thought to free trapped charge and partially restore the dynamics of the uncycled device (Knowles, 1977).

Quenching. Once an EC device has been colored, it will remain colored if it has the ability to store charge. In practice all devices have leakage currents and will quench after some period of time. OCM is based on the ability of the device to store charge. The parameters to determine OCM are not generally well defined. Both proton- and lithium-based devices (Mohaptra, 1978) in inorganic solid systems can show good OCM, lasting several hours. The properties of quenching in devices are very much related to the materials and construction of the device.

Volume Changes. Volume changes have been reported for sputtered iridium oxide anodes (Hackwood et al., 1981). Iridium oxide thicknesses on quartz substrates were measured as deposited, after immersion in $0.5 \mathrm{M} \mathrm{H}_{2} \mathrm{SO}_{4}$, after successive coloring and bleaching, and on further immersion after two coloring-bleaching cycles. The experiments showed the anodes expand on incorporation of water; the kinetics of water uptake is greatly increased by the coloring and bleaching cycles. Hydration increases the response time. The anode volume expands on coloring and contracts on bleaching, but there is a net volume increase during each complete cycle for the first few cycles until a steady state thickness is reached. The volume changes are attributed to the porous nature of the films.

Temperature Dependence and Decomposition. The temperature dependence of cyclic switching is important to the lifetime of the eiectrochromic device. A device consisting of Glass/ITO/a- $\mathrm{WO}_{3} / \mathrm{LiClO}_{4}+$ Redox/ITO/glass has been studied for thermal aging (Nagai et al., 1986b, Kamimori et al., 1987). As shown in Figure 5-3, color/bleaching cycles were performed using a dc potential of $1.0 \mathrm{~V}$ or $-1.0 \mathrm{~V}$ at $60 \mathrm{~s}$ intervals for more than $10^{5}$ cycles. Cells were cycled for more than 30 days at different temperatures of $22,50,60$, and $90^{\circ} \mathrm{C}$. At higher temperatures, the response time of the device became slower and there was a decline in charge injection levels. After a few days a constant charge injection level was achieved. As shown, the injected charge per unit area drops to $14 \mathrm{mC} / \mathrm{cm}^{2}$ from about $16 \mathrm{mC} / \mathrm{cm}^{2}$ at $22^{\circ} \mathrm{C}$. However, the injected charge drops and becomes constant at $6 \mathrm{mc} / \mathrm{cm}^{2}$ at $90^{\circ} \mathrm{C}$.

As suggested by studies that have been performed on $\mathrm{LiClO}_{4}+\mathrm{PC}$ (Kase et al., 1986), thermal stability may also be important for devices with polymer electrolytes. Decomposition was noted at $10^{3} \mathrm{~h}$ at $60^{\circ} \mathrm{C}, 300 \mathrm{~h}$ at $70^{\circ} \mathrm{C}, 200 \mathrm{~h}$ at $80^{\circ} \mathrm{C}$, and $15 \mathrm{~h}$ at $90^{\circ} \mathrm{C}$. Gas bubbles usually formed in the device during decomposition.

\subsubsection{Degradation Mechanisms}

Several mechanisms for specific EC devices have been established. These include film dissolution, corrosion, transparent conductor (ITO) etching, and hydrogen embrittlement. 


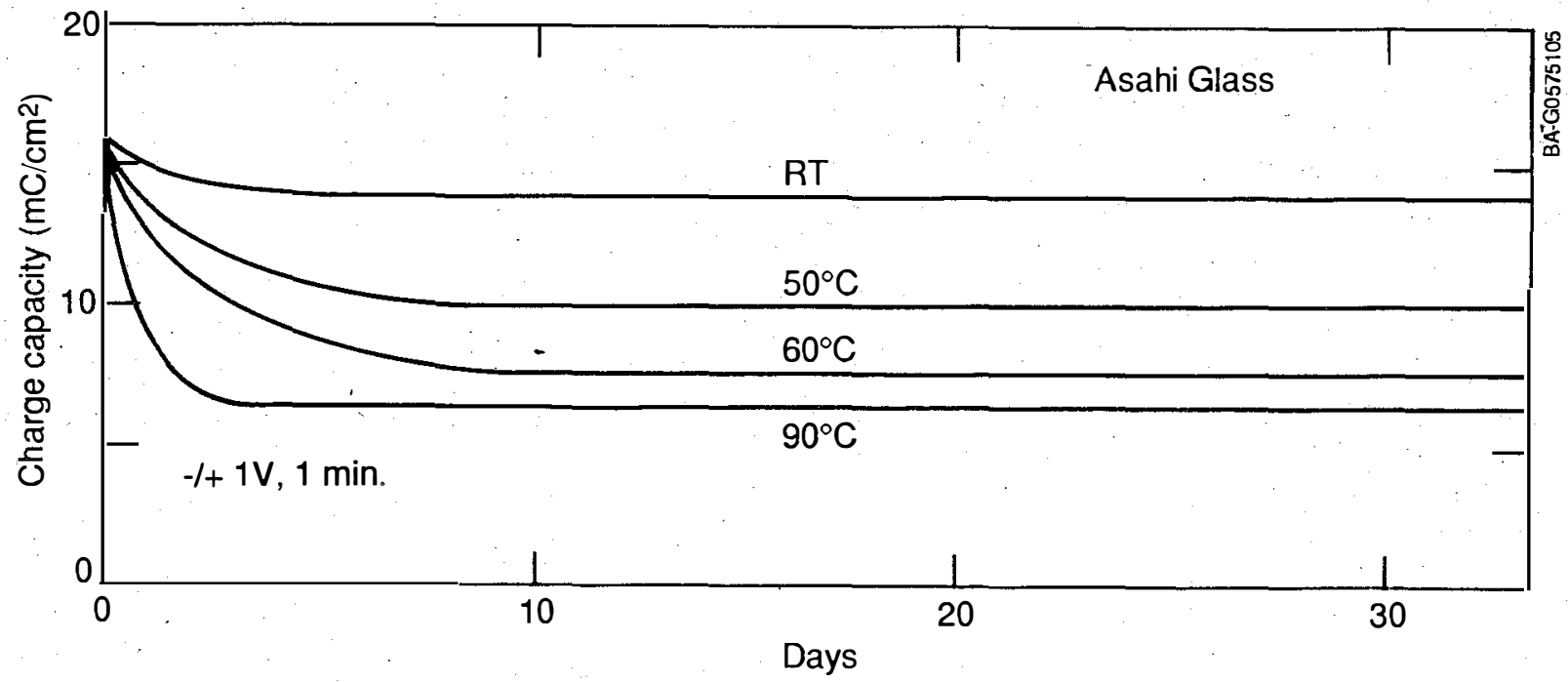

Figure 5-3. The decline in charge capacity (charge per unit area) with time and temperature for a tungsten oxide electrochromic device (ITO/a-WO $3 / \mathrm{LiClO}_{4}+$ Redox/ITO). This device was cycled at $+/-1 \mathrm{~V}$ potential at $60 \mathrm{~s}$ intervals over the period of testing (Nagai et al., 1984, 1986a, 1986b; Kamimori et al., 1987).

Film Dissolution. Many authors have noted the dissolution of $\mathrm{a}^{-\mathrm{WO}_{3}} \mathrm{films}$ in water and in acidic environments, following the reaction: a- $\mathrm{WO}_{3}+6 \mathrm{H}^{+}$ $-->\mathrm{W}^{6+}$ (solution) $+3 / 20_{2}$. The dissolution of ${\mathrm{c}-W O_{3}}_{3}$ is considerably slower. The dissolution rate of $a-\mathrm{WO}_{3}$ in water has been estimated as $2.5 \mu \mathrm{m} /$ day (Randin, 1978). The dissolution rate ( $R$ ) is a function of the electrolyte $\mathrm{pH}$, e.g. $1 \mu \mathrm{m} / \mathrm{yr}$ at $\mathrm{pH}=0$ and $10^{3} \mu \mathrm{m} / \mathrm{yr}$ at $\mathrm{pH}=6$, following the equation $\mathrm{R}=$ $\mathrm{k} 10^{0} .33 \mathrm{pH}$. At higher $\mathrm{pH}$ values the rate increases. For a $\mathrm{pH}=9$ the rate is $10^{4} \mathrm{~m} / \mathrm{yr}$, following the equation $\mathrm{R}=\mathrm{k}_{2} 10^{0.66 \mathrm{pH}}$. These values (shown in Figure 5-4) were obtained for a flowing electrolyte (Faughnan and Crandall, 1980). For a static sealed electrolyte these rates decreased by an order of magnitude to 2 to $2.5 \mathrm{~nm} /$ day at $50^{\circ} \mathrm{C}$ in a glycerin- $\mathrm{H}_{2} \mathrm{SO}_{4}$ solution (Randin, 1978). This effect can pose a shelflife problem for these devices.

It is thought that $\mathrm{a}^{-\mathrm{WO}_{3}}$ films are in the form of trimeric clusters that are weakly bound to each other with water bridge bonds. This results in a very open microstructure and high proton mobilities, giving higher switching speeds. This structure has been identified as the xerogel structure, consisting of a highly-porous, low-density oxide (Schlotter and Pickelmann, 1982). Unfortunately this structure is subject to dissolution and cyclic erosion. When the film dissolves, it forms metatungstate or polytungstate ions (Arnoldussen, 1978). To reduce this problem, alkali salts in aprotic (nonaqueous) electrolytes have been used, but this decreases device response.

Although the dissolution mechanism is established and understood, it is specific to $\mathrm{WO}_{3}$ and aqueous electrolytes. This information might be useful where solid electrolytes are used for the IC when considering degradative interface reactions. 


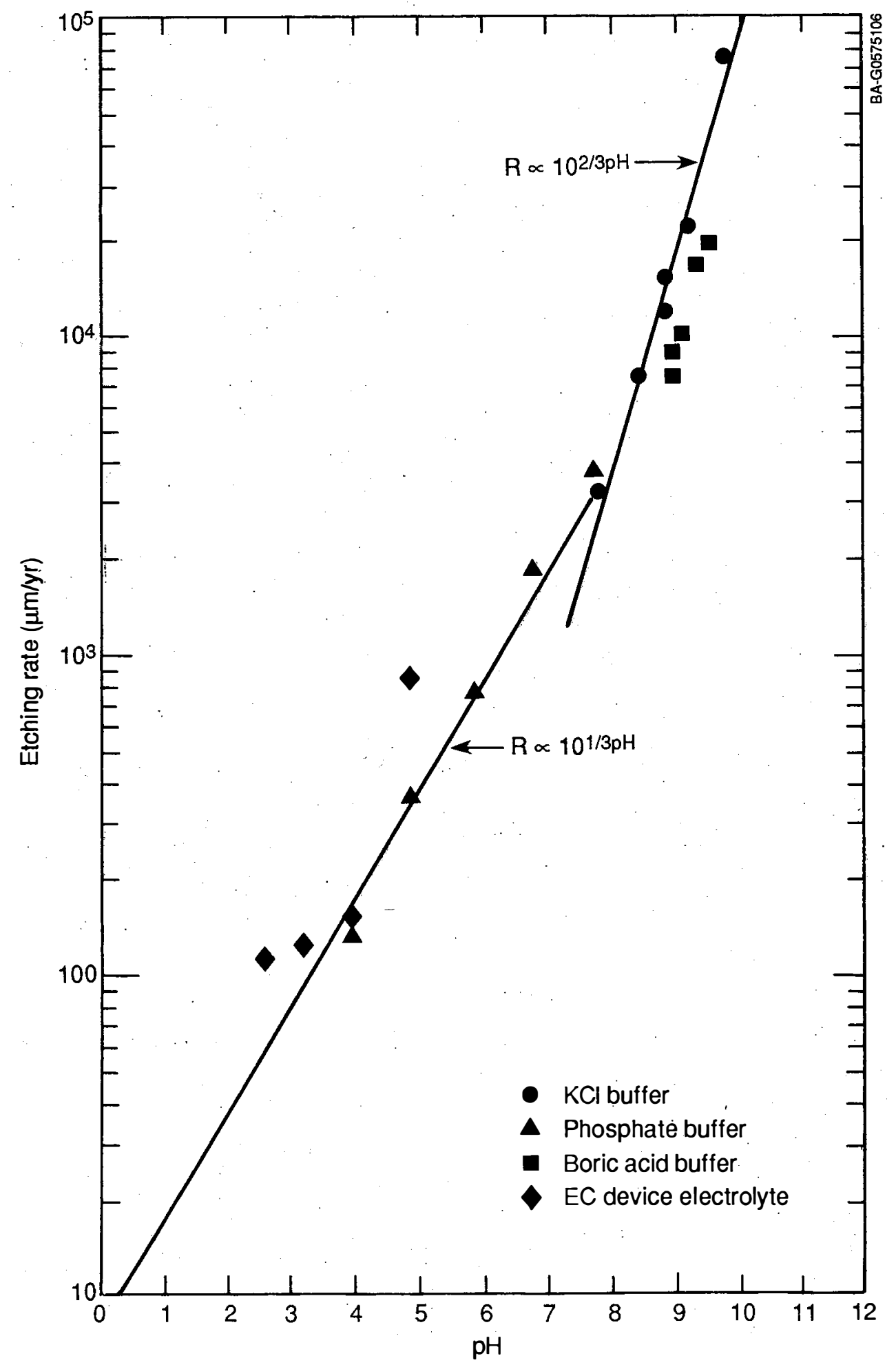

Figure 5-4. Etch rate ( $R$ ) vs $\mathrm{pH}$ for $\mathrm{WO}_{3}$ films immersed in different buffered electrolyte solutions. (After Faughnan and Crandall, 1980 ). 
Transparent Conductor Etching. Two different, mechanisms of degradation of ITO conductor layers have been identified. As suggested earlier, the transparent conductor ITO has some of the best optical and conduction properties but is sensitive to etching in acids. ITO has a reduction potential of $-1.0 \mathrm{~V}$ to $-2.5 \mathrm{~V}$ (SCE) depending on the $\mathrm{pH}$ of the electrolyte (Kamimori et a1., 1987). ITO can be reduced by dissolution in acid, $\mathrm{In}_{2} \mathrm{O}_{3}+6 \mathrm{H}^{+} \rightarrow 2 \mathrm{In}^{3+}+3 \mathrm{H}_{2} \mathrm{O}$, by electrochemical dissolution, $\mathrm{In}_{2} \mathrm{O}_{3}+6 \mathrm{H}^{+}+6 \mathrm{e} \rightarrow 2 \mathrm{In}+3 \mathrm{H}_{2} \mathrm{O}$, and $\mathrm{In} \rightarrow \mathrm{In}^{3+}+$ 3e-. Doped $\mathrm{SnO}_{2}$ has a much better etch resistance, but ITO has better optical and electrical properties. However, in strong acids, doped $\mathrm{SnO}_{2}$ can be reduced electrochemically by $\mathrm{SnO}_{2}-->\mathrm{Sn}^{+4}+\mathrm{O}_{2}+4 e^{-}$(Randin, 1978). In the $\mathrm{SnO}_{2} / \mathrm{a}-\mathrm{WO}_{3} /$ P-AMPS/C device, the reduction of $\mathrm{SnO}_{2}$ is seen at potentials above $1.0 \mathrm{~V}$. To solve this problem, a protective cover has been used for areas in direct contact with the acidic electrolyte (Cogan et al., 1987). However, knowing this mechanism, again, may be of limited usefulness in an all-solid-state EC window.

Ion Trapping. More recently, lithium ions have passed through electrode materials and are reducing the performance of ITO layers (Cogan and Rauh, 1989). These are recent results and further research should be conducted to determine the magnitude and seriousness of the problem.

\subsubsection{Other Degradation Problems}

Other forms of performance losses may result when used in buildings. These losses, which may result from reliability and/or durability problems not addressed in Sections 5.1.1 through 5.1.4, include scratches and their concommitant influence on mechanical stability, delamination at interfaces, building vibrations, rapid thermal expansion or contraction, electrical isolation (safety), and continuity of the electrical connections (e.g., rupture or corrosion of the conductors). The latter should not present difficulties because of past successful experience with electrically heated windows and with photovoltaic modules. Other problems such as the development of blotchiness, failure during use below $0^{\circ} \mathrm{C}$, and hot spots in the electrical connections are quality assurance issues. These other reliability, durability, and quality assurance problems will need to be addressed at some future date, but are premature for the purpose of this document.

\subsubsection{Summary of Degradation Stresses, Modes, Effects, and Mechanisms}

Various EC windows have been subjected to the following degradative stresses or conditions: cyclic voltage and current, temperature, humidity, UV radiation, internal water, outdoor exposure, static conditions, or Weather-Ometer. These have produced the degradative modes, effects, or stresses 1 isted in Table 5-1 as summarized from various articles. The stresses or conditions have been imposed on the different device types as summarized in Table 5-2. As seen in Table 5-1, most of the types of degradation have been triggered using cyclic voltage and current, several have been caused by temperature and internal water, and only one type of degradation has resulted from the other stresses. The stresses or conditions most frequently applied to different device types have been cyclic voltage and current (in nearly all cases), temperature, UV radiation, and internal water. The number of investigations that have studied the degradative influence of humidity, static conditions, elevated (stagnation) temperatures, outdoor exposure (real-time testing), and Weather-Ometer environments (accelerated) testing is minimal. The four latter 
Table 5-1. Matrix of Various Studiest in which a Degradation Mechanism, Effect, or Mode has Resulted from Various Degradative Stresses or Conditions Imposed (Adapted from Lampert, 1990c).

\begin{tabular}{|c|c|c|c|c|c|c|c|c|}
\hline \multirow[b]{2}{*}{$\begin{array}{l}\text { Degradation Mode } \\
\text { Effect, or Mechanism }\end{array}$} & \multicolumn{8}{|c|}{ Stress or Condition } \\
\hline & $\begin{array}{l}\text { Cyclic Voltage } \\
\text { and Current }\end{array}$ & Temperature & Humidity & $\begin{array}{l}\text { UV } \\
\text { Radiation }\end{array}$ & $\begin{array}{l}\text { Outdoor } \\
\text { Exposure }\end{array}$ & WOM $^{+}$ & $\begin{array}{l}\text { Static } \\
\text { Conditions }\end{array}$ & $\begin{array}{l}\text { Internal } \\
\text { Water }\end{array}$ \\
\hline A. Film Dissolution & $1,4,17,22 *$ & 4,22 & & & & & 1,22 & 4,22 \\
\hline $\begin{array}{l}\text { B. Cyclic Changes (Charge Capacity } \\
\text { and Optical) }\end{array}$ & $1-4,12,17,23$ & & & & & 10,20 & & 18 \\
\hline
\end{tabular}

D. Mechanical (Hydrogen

Embritt lement) 22

\begin{tabular}{lll}
\hline E. Transparent Conductor Etching & 6,10 & 22
\end{tabular}

F. Gas Generation $\quad 4,26$

\begin{tabular}{lccc}
\hline G. Humidity Dependence & $8,9,114,15,24$ & $8,9,24$ & $8,9,14$, \\
\end{tabular}

\begin{tabular}{llcl}
\hline H. Secondary Chemical Reactions & 16 & $10,12,17,20$ & \\
\hline I. UV Photochromism & 12 & 10,20
\end{tabular}

J. Thermal Dependence and Decomposition

\section{Weather-Ometer.}

*Numbered references above correspond to bibliographic references as follows:

$\begin{array}{ll}\text { 1. Arnoldussen, 1978 } & \text { 10. Kamimori, et al., } 1987 \\ \text { 2. Carpenter, et al., 1987 } & 11 . \text { Kase, et al., 1986 } \\ \text { 3. Cogan, et al., 1987 } & 12 . \text { Knowles, 1977 } \\ \text { 4. Faughnan, Crandall, 1980 } & 13 . \text { Lampert, 1990b } \\ \text { 5. Fleisch, Mains, 1982 } & 14 . \text { Lusis, et al., 1982 } \\ \text { 6. Giglia, Haacke, 1982 } & \text { 15. Lusis, et al., 1984 } \\ \text { 7. Gissler, Memming, 1977 } & \text { 16. Masumi, et al., 1982 } \\ \text { 8. Hajimoto, et al., 1979 } & \text { 18. Morita, Washida, 1982 } \\ \text { 9. Hughes, Lloyd, 1977 p } & \end{array}$

19. Naga i, et al., 1986a

20. Nagai, et al., 1986b

21. Pennisi, Lampert, 1988

23. Schlotter, Pickelmann, 1982

24. Stocker, et al., 1978

25. Svensson, Granquist, 1987

26. Yoshimura, et al., 1982

9. Hughes, Lloyd, $1977 \mathrm{P}$

18. Nagai, et al., 1984

27. Yu, et al., 1987 
Table 5-2. Matrix of Various Studies* in which a Specific Device has had Various Degradative Stresses or Conditions Imposed (Adapted from Lampert, 1990c).

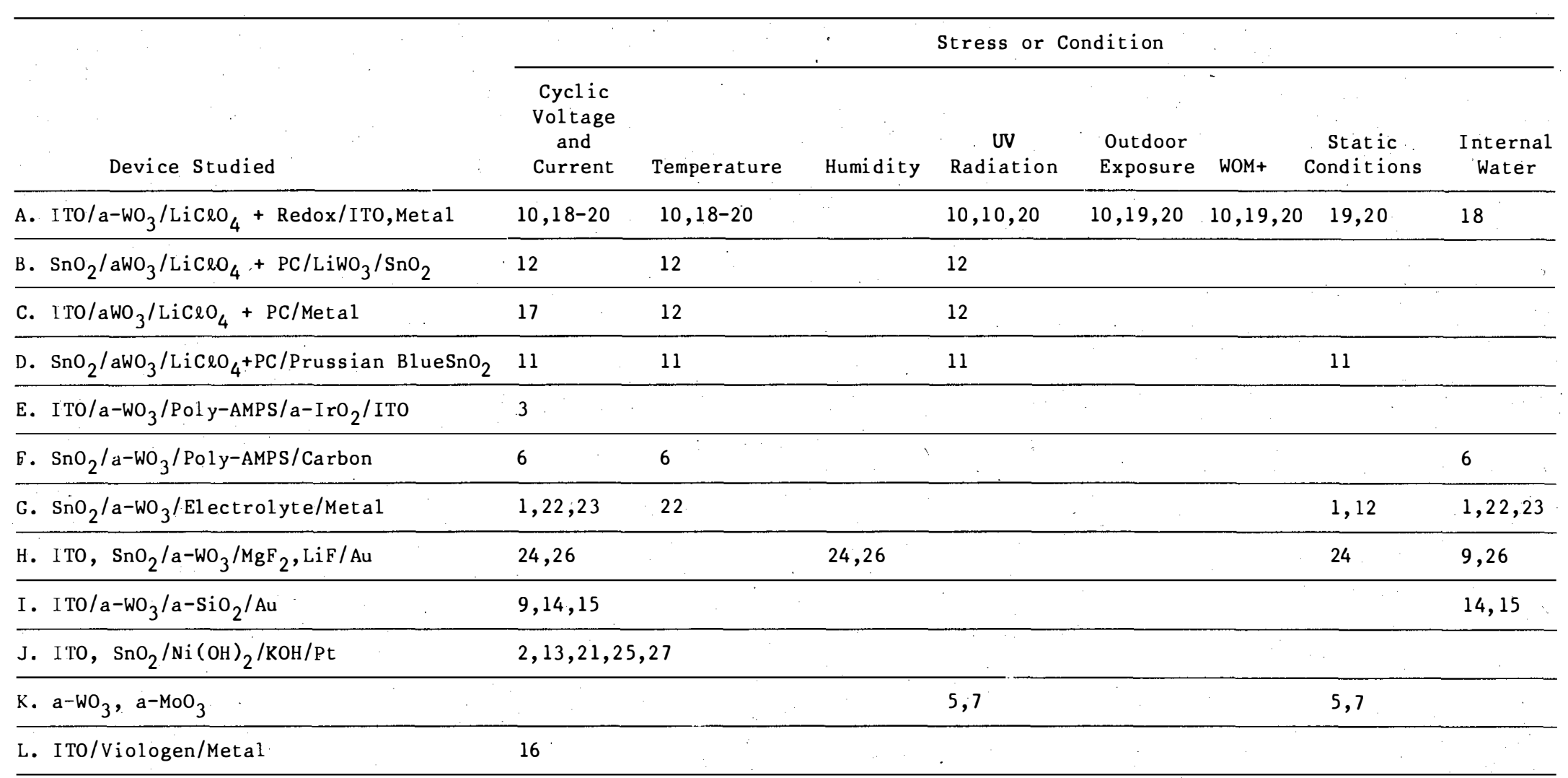

* See numbered references in Table 5-1 for key to bibliographic references in this Table.

Wea ther-Ometer 
stresses clearly represent choice opportunities for testing the stability/ durability of EC windows in future work.

\subsection{Performance Measurements for Real-Time and Accelerated Life Testing}

In principle, a complete characterization of an EC window by all the measurements mentioned in Section 4.2 .1 might be necessary to establish all aspects of performance losses by the device. In practice, scientists must find ways to secure adequate information about EC window durability at a minimum cost. For example, in a silver-glass mirror testing program (Masterson et al., 1983), a complete test matrix of six different mirrors and the measurement of al1 the mirror characterization parameters over the testing period would have required obtaining more than 77,600 separate data inputs. Statistical procedures were applied, and after a 2-year effort, it was determined that the constancy of one measurement was adequate for concluding the mirror had no loss in the primary performance requirement. (The latter was the specular reflectance of all solar energy, which included radiation from 200 to $2600 \mathrm{~nm}$, that could be used in a mirror field for central receiver applications.) The simplified approach found for silver-glass mirrors may not be technically available for EC windows, but it is a goal worth pursuing. Several crucially important measurements required during the testing of prototype EC windows are discussed below.

\subsubsection{Wavelength Dependence of Transmittance and Reflectance in Colored/Bleached States}

Transmittance is clearly the most important performance parameter for a functioning EC window. The ambiguity or risk for misinterpretation of monitoring only a single wavelength is evident by inspecting the data in Figure 4-2 at a particular wavelength. Although the data in Figure 4-2 are for three different $W_{3}$ films, it is possible similar wavelength differences will result in a single film as it degrades. However, it may be possible to select certain wavelengths for real-time monitoring as guides for estimating when a performance loss occurs. This can be seen from Figure 5-5, where \% $\mathrm{T}$ is strongly temperature dependent below $\underline{500 \mathrm{~nm}}$. It may even be possible for an absorption maximum to shift in wavelength for a device that is still performing properly.

Reflectance as a function of wavelength is also an important performance parameter. There is insufficient history on $R(\lambda)$ measurements because not all research groups measure it, nor is there a history of correlating $R(\lambda)$ with performance degradation.

\subsubsection{Atomic Percent of Injected Charge}

The measure of injected charge is not quantified in absolute terms as discussed in Section 4.2.1. To correlate the transmittance change with the number of color centers requires knowing the number of ions injected into a lattice of a known amount. For a given device, $Q$ in $\mathrm{C} / \mathrm{cm}^{2}$ is used by most groups and it may even be a standard. However, the ambiguity of this quantity if thickness, density, or compositional changes occur is obvious. Some better measure of injected charge is needed; in the meantime, the scientific community must agree on some measurement of injected charge that provides the least risk for misinterpretation. 


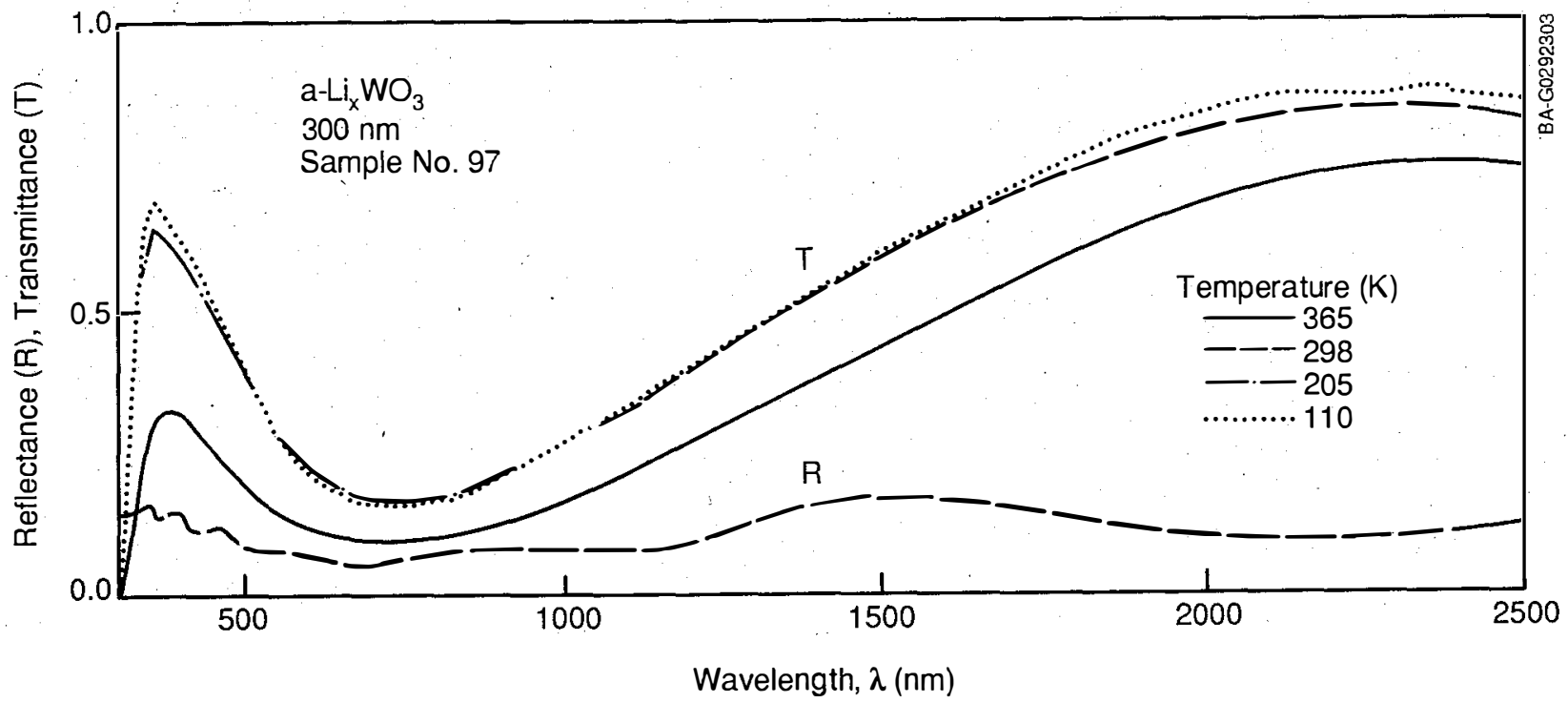

Figure 5-5. Optical transmission spectra of a $\mathrm{Li}_{\mathbf{x}} \mathrm{WO}_{3}$ thin film on soda-1imesilica glass. (After Benson and Svensson, 1990).

\subsubsection{Time Dependent Change in the Transmittance and Reflectance During Coloring/Bleaching}

Performance degradation at the chosen end-points of an applied potential that yields the colored/bleached state may be monitored by tracking the rate at which coloring or bleaching occurs. This might be accomplished from response time measurements, but would be best accomplished by monitoring $\Delta \% \mathrm{~T}(t)$ or $\Delta \% A(t)$. A set of curves is shown in Figure 5-6 to illustrate the concept. These data are for an a- $\mathrm{WO}_{3} / \mathrm{IrO}_{2}$ EC device using $\mathrm{H}^{+}$counter ions that was switched to 1.2V and held at that voltage. For each of the 8000 cycles, the voltage was switched to provide the maximum and minimum optical limits (Cogan, 1990). The changes in transmittance and reflectance have been reported for an ITO/WO $/ \mathrm{LiNbO}_{3} / \mathrm{In}_{2} \mathrm{O}_{3} / \mathrm{ITO}$ device before and after 3000 cycles for coloring and bleaching at $3.0 \mathrm{~V}$ (Seward et al., 1987). Kinetic data as the approach to the final state often indicate changes in the rate of approach, even though the same final state is reached in less than $2 \mathrm{~min}$. Thus, these data may be early indicators that a degradation in performances can be anticipated. As has been shown, response time measurements are temperature dependent (Hackwood et al., 1981) for sputtered iridium oxide films (Figure 5-7). Their report states, "the response times, being electrolyte independent, are representative of a process taking place within the electrochromic material." For all conditions studied in their work, the initial charge injection or extraction varies with times as $\sim t^{1 / 2}$, suggesting a diffusion-limited process. They found an activation energy of $\sim 0.5 \mathrm{eV}$, which is a low value for an ion diffusion process, lying in the range of typical fast-ion conductors. This value is also at the low end of activation energies for grain boundary diffusion, which typically range from 0.5 to $1.25 \mathrm{eV}$ (Poate et al., 1978). The data in Figure 5-7 extrapolate to a response time that is four orders of magnitude different between $80^{\circ} \mathrm{C}$ and $-30^{\circ} \mathrm{C}$. Measuring the kinetics of the response times at these two extremes might be a fruitful area for laboratory studies, especially at the lower temperatures where the kinetic processes are much slower. 


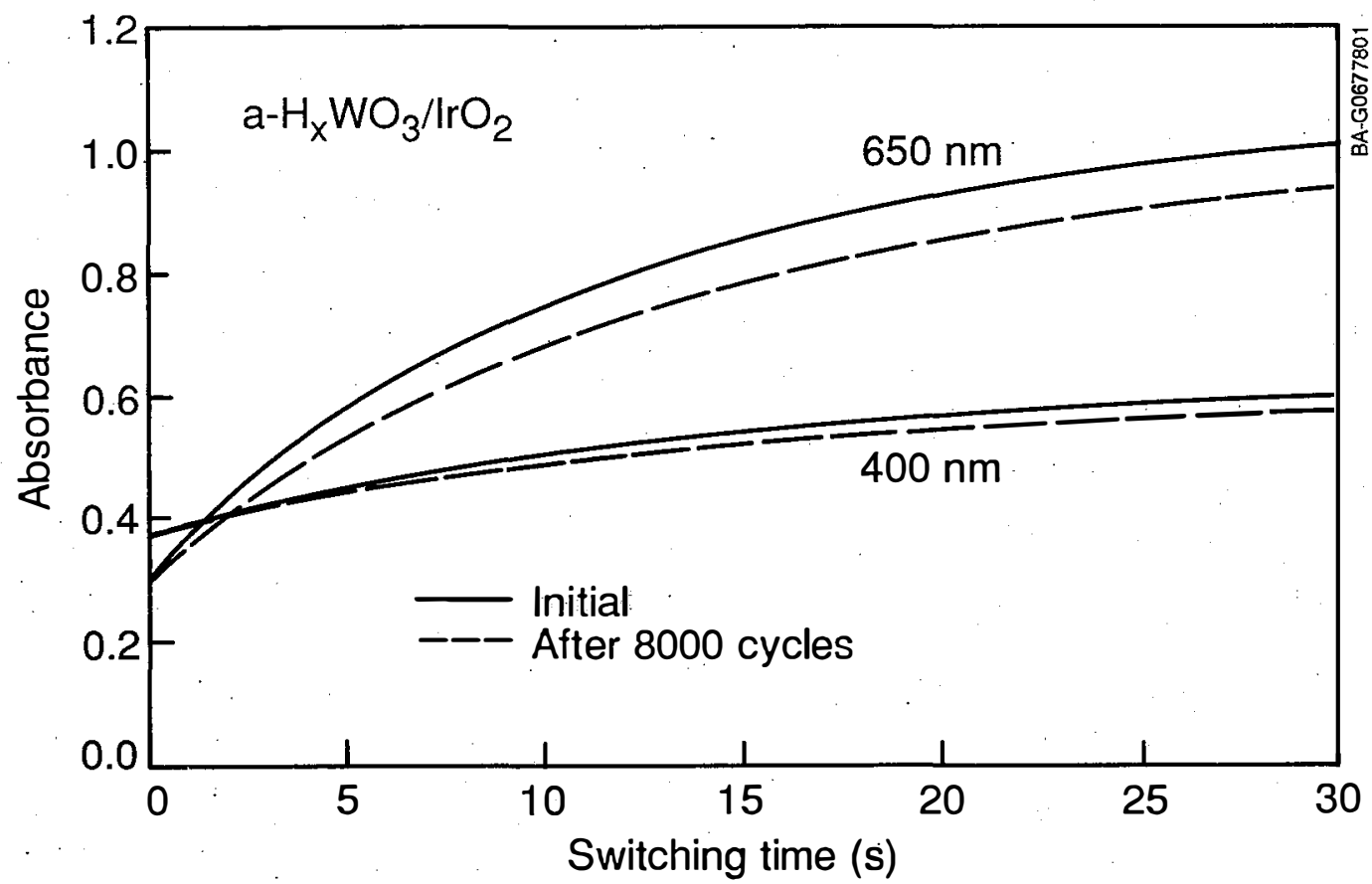

Figure 5-6. Change in absorbance with switching time before and after potentiostat cycling through 8000 cycles (after Cogan, 1990).

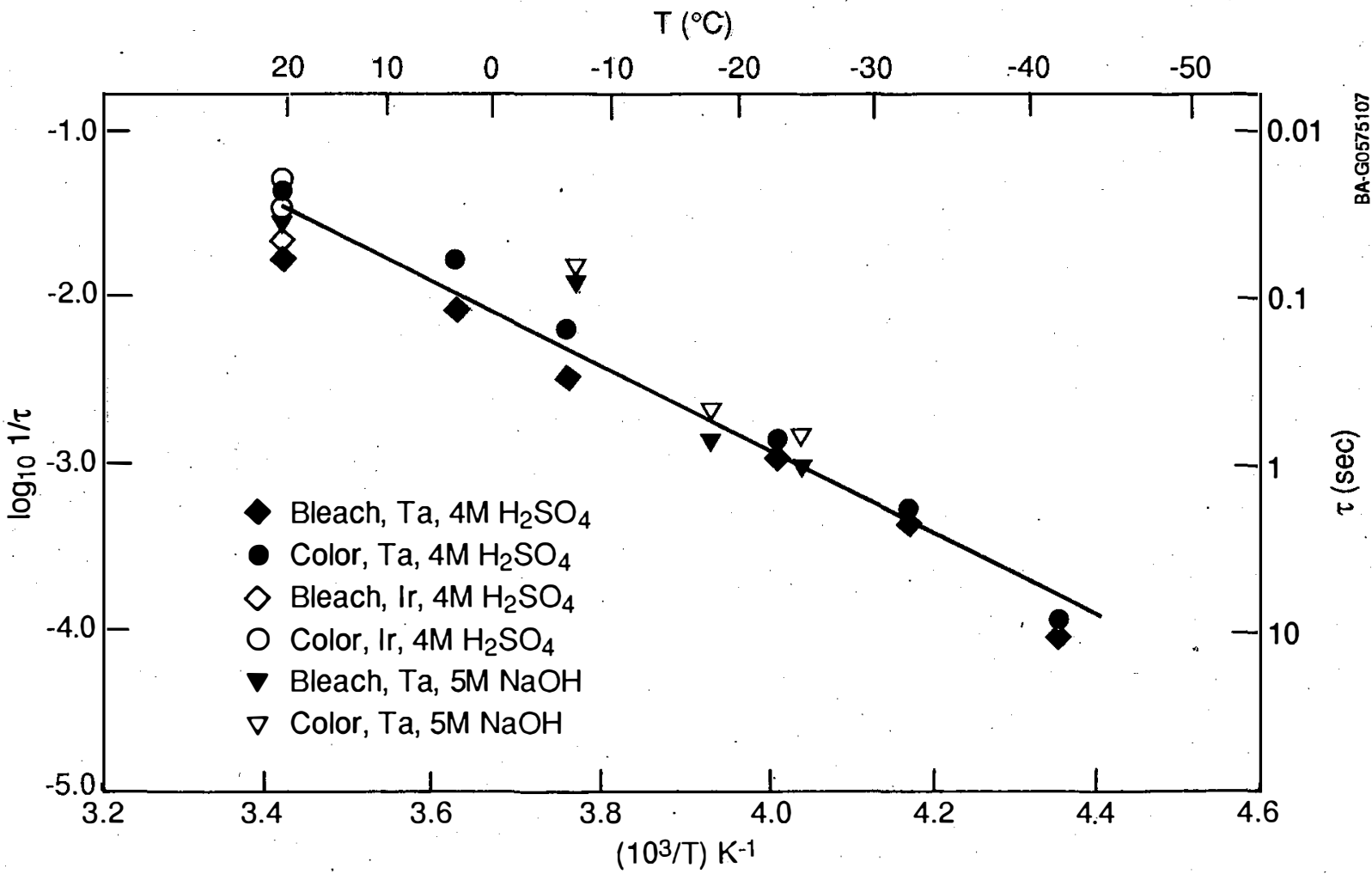

Figure 5-7. Temperature dependence of the coloration and bleaching times of 200- $\AA$-thick sputtered iridium oxide films deposited on tantalum and iridium substrates, and studied in concentrated acidic and basic aqueous solutions. The coloration and bleaching times are defined as the times required to insert or extract $20 \mathrm{mC} / \mathrm{cm}^{2}$ of charge following a voltage step of $1 \mathrm{~V}$ amplitude (from Hackwood et a1., 1980). 


\subsection{Methods/Procedures for Real-Time Testing}

As far as we can determine, there are no uniformly accepted procedures or methods for the real-time testing of an EC window. However, we can suggest what procedures might be used for comparing the relative durability of different EC windows or similar EC windows made by different laboratories. The aspects in need of standardization include the size of the device and the sheet resistivity of the TC. The layer thicknesses of the entire multilayer stack also need to be the same when comparing EC windows made from the same materials but by different laboratories or under different processing conditions.

\subsubsection{Cyclic Tests Emphasizing Electrical Properties of EC Windows}

Electrical properties must be emphasized for cyclic tests. Voltammetry curves produced by potentiostats that simulate use conditions are needed, but how they will be standardized is a problem. Variables include the voltammetry cycle time, cycles/unit time (are there relaxation effects?), the magnitude of the extremes of cyclic potential, and the wave form of the driving potential. As indicated in Section 4.2.1, these important questions require answers for standardization. The potential extremes corresponding to those needed to provide the designed (or chosen) colored and bleached states should be strictly used, because simulated real time use would be compromised.

The transmittance response during cyclic tests using voltammetry must be measured. Assuming the entire I-V dynamics and range are standardized, the same $T(\lambda)$ should be reproduced at each point during the cycle. The obvious need is to take $T(\lambda)$ at the extremes in applied potential. When a large number of cycles are employed $\mathrm{T}$ at a $\lambda$ might be a suitable probe, perhaps, with a laser, detector, and fiber optic for in-situ monitoring. Complete $T(\lambda)$ data would then be required after a large number of cycles, e.g., for a device to be cycled 100,000 times, $\mathrm{T}(\lambda)$ after $100,300,1000,3000,10,000,18,000,30,000$, 56,000 and 100,000 cycles could narrow the time domain in which performance degradation occurs.

Finally, structural or morphological changes may occur in the EC, CE, and IC films during real-time use. These can have a profound effect on the diffusion rates of injected charge, as has been known for decades for thin films (e.g., Poate et al., 1978). Thus, a non-destructive monitor to probe the structure and morphology of the thin films in an EC device would be needed to avoid misinterpretation of response time data.

\subsubsection{Cyclic Tests Under Use or Storage Conditions}

The standardized cyclic tests outlined in the previous section must be used under at least two simulated real-time conditions. The first is simulating use in a building application. Here, the variables are cyclic UV, cyclic $T$ corresponding to diurnal cycles, and "catastrophic $\Delta T$ excursions" corresponding to cloud cover and sudden exposure of the sun. Temperature extremes must be identified, the rate of $\Delta T$ excursions must be simulated, and the $U V$ intensity matched to solar incidence. As work by Webb et al (1984) has shown, special care must be taken with solar simulators that produce UV wavelengths to well below $285 \mathrm{~nm}$. Considerable damage can be done by shorter wavelength UV that does not simulate reality, and can lead to a misinterpretation of the 
true device lifetime. The second real-time condition is to simulate shelflife. The variables here are probably a constant $\mathrm{T}\left(\sim 22^{\circ} \mathrm{C}\right)$, no $\mathrm{UV}$, but may include high relative humidity $(\mathrm{RH})$ concentrations of pollutant gases.

\subsection{Methods and Procedures for Accelerated Testing}

The introductory paragraph in Section 5.3 also applies here, as does the discussion in Section 5.3.1. However, a voltammetry cyclic accelerated test presents a most intriguing experimental problem. If an EC window is cycled once every $10 \mathrm{~h}$ and stored for $14 \mathrm{~h}$, what effect does using cyclic voltammetry once every $6 \mathrm{~min}$ (acceleration factor of at least 100) do to the physical processes occurring in the materials in the EC window? Are the mechanisms that result in performance degradation perturbed? Do the cyclic tests provide a proper basis for lifetime projections or do they yield a valid indication of relative durability of different EC windows?

Accelerated testing can also be accomplished using elevated temperature, RH, and exposure to UV. Two widely used techniques are Weather-Ometers and QUV testing devices. Weather-Ometer and QUV are registered trademarks of the Atlas Electric Devices Co. and the Q-Panel Co., respectively. Each device has a chamber for mounting specimens that can be subjected to elevated temperature, controlled RH or a water condensate, and UV radiation. In a WeatherOmeter used for silver/polymer mirror testing (Schissel and Neidlinger, 1987), specimens are typically subjected to UV (or no UV), $60^{\circ} \mathrm{C}$, and $80 \% \mathrm{RH}$. A xenon arc lamp with a filter cutoff to match the terrestrial solar spectrum supplies the UV 1ight. The QUV test cyclically uses $4 \mathrm{~h}$ of UV exposure (from fluorescent lamps) at $60^{\circ} \mathrm{C}$ and $4 \mathrm{~h}$ of condensed water exposure at $40^{\circ} \mathrm{C}$ (ASTM, G.53-77). The accelerated weathering devices are used for comparison only; it is not possible to state which device provides the harsher test for any particular mirror material or how the accelerated tests compare with outdoor (real-time) weathering. The spectral distribution for the irradiation used in the two devices is compared with solar radiation (air mass 1.5 ) in Figure 5-8.

For Weather-Ometer and QUV accelerated testing, we ask questions about mechanisms similar to those in the first paragraph in this section. What is the potential of an accelerated test for causing a change in molecular mechanisms that departs from reality? These questions apply when one is tempted to choose an elevated $\mathrm{T}$ of $120^{\circ} \mathrm{C}$ when real-time use is between 0 and $80^{\circ} \mathrm{C}$, and to use temperature cycle times of $1 \mathrm{~h}$ or even $6 \mathrm{~min}$ when real-time use is once every $10 \mathrm{~h}$. For UV exposure tests (at a properly matched.UV intensity versus wavelength), how many "equivalent suns" can be used? 10? 100? 1000? If RH is a factor, what meaning does a dew-point QUV cycle have on a device that will normally be exposed to water vapor at RHs of $40 \%$ to $90 \%$ ? For urban environments, what "enhanced" concentrations of pollutants $\left(\mathrm{SO}_{2}, \mathrm{NO}_{\mathrm{x}}, \mathrm{CO}, \mathrm{O}_{3}\right.$, etc.) can be used to accelerate a performance loss, and not change a mechanism. Finally, the synergism of combined tests of $T$, cyclic $T$, UV, RH, pollutants, and possibly even freeze/thaw treatments must be considered. It must be evident at this stage that the calculation of acceleration factors can only be technically feasible when adequate research and testing has been carried out to support lifetime projections under real-time use from the accelerated life testing of the device(s). We can only raise these issues as questions for resolution for durability testing of EC windows. 


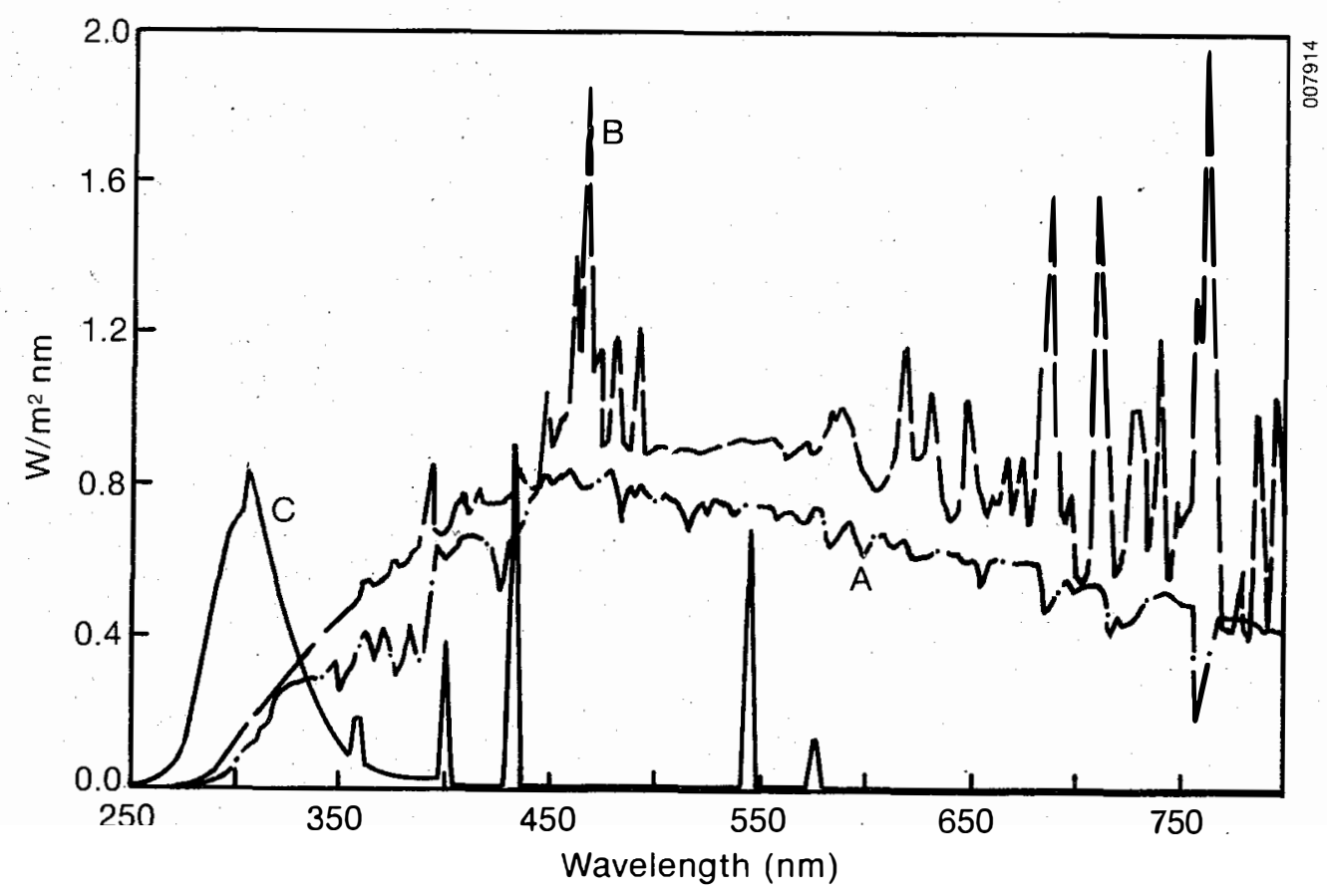

Figure 5-8. A comparison of the relative spectral distribution of power from sunlight at air mass 1.5 (A), Weather-Ometer (B), and QUV (c) light sources. 


\subsection{RECOMENDATIONS}

Preliminary recommendations are made in this section. These recommendations provide a foundation for further discussion of the issues of the required parameters and test methods for studies that are (1) primarily for laboratory research and evaluation, (2) for prototype evaluation, and (3) for durability evaluation under real-time and accelerated testing conditions. The natural progress of (1) through (3) is shown schematically in Figure 6-1. A large number of different EC windows, components, and materials are represented for laboratory research; of these, some systems will be chosen for prototype evaluation. The latter will be complete EC windows with a defined size of $1 \mathrm{ft}^{2}$ $(30 \times 30 \mathrm{~cm})$, defined materials, and defined layer thicknesses. Prototypes may simply be larger versions of smaller devices studied in (1). During prototype evaluation, additional research issues will be generated, and additional laboratory research may be necessary to improve the prototype. Some of the prototypes will successfully pass the performance criteria required of an EC window, and these will be subjected to durability/stability/lifetime testing (3). During durability testing, additional research issues will most likely result from analysis of the results, and additional laboratory research may be necessary to improve the device before proceeding with further testing. Successful prototypes from the durability testing (3) will become candidates for commercialization. For this purpose, the parameters and measurements from Table 4-1 are 1isted in Table 6-1.

The parameters and measurements 1 isted in Table 6-1 have been reduced to those deemed essential to EC window research and development for the progression shown in Figure 6-1. Our recommendations for these are categorized as most important (1), important (2), and helpful (3) for a given device. Those that are a property of a material, part of a device design, or a parameter from reduction of other data are labeled NA. We have also added surface analysis (Czanderna, 1975) as important for diagnostic evaluation of compositional changes and related phenomena, ranging from deducing mechanisms to estab1 ishing causes in performance losses. A recommended test matrix is given in Table 6-2 for stages (1), (2), and (3) of Figure 6-1. 


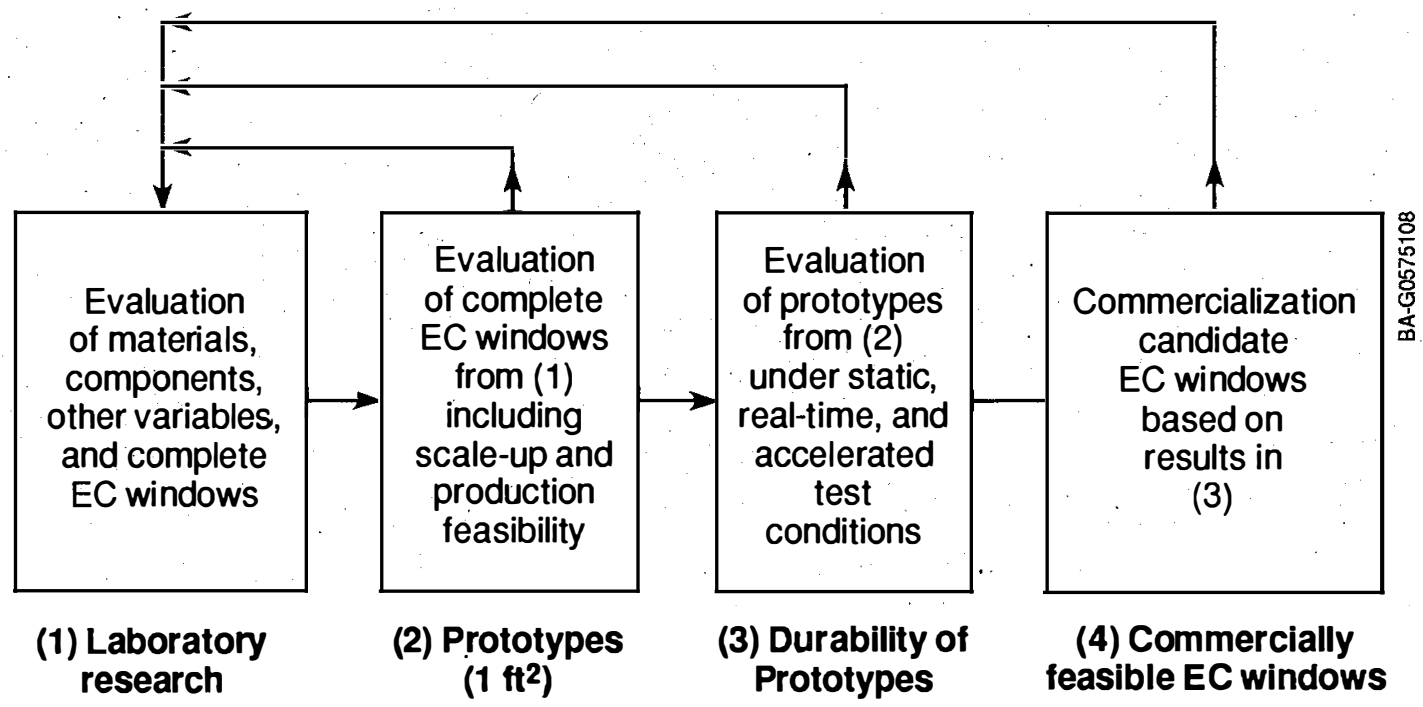

Figure 6-1. Flow of EC window testing from (1) laboratory research and evaluation, to (2) prototype testing, to (3) durability testing, and finally to (4) commercialization 
Table 6-1. Categorization of Parameters and Measurements for Different Stages of EC Window R and D ( 1 = highest priority to $3=$ lowest priority, $D=$ derivable from other measurements, $E=$ established from earlier laboratory research, and $N A=$ not applicable ${ }^{*}$ )

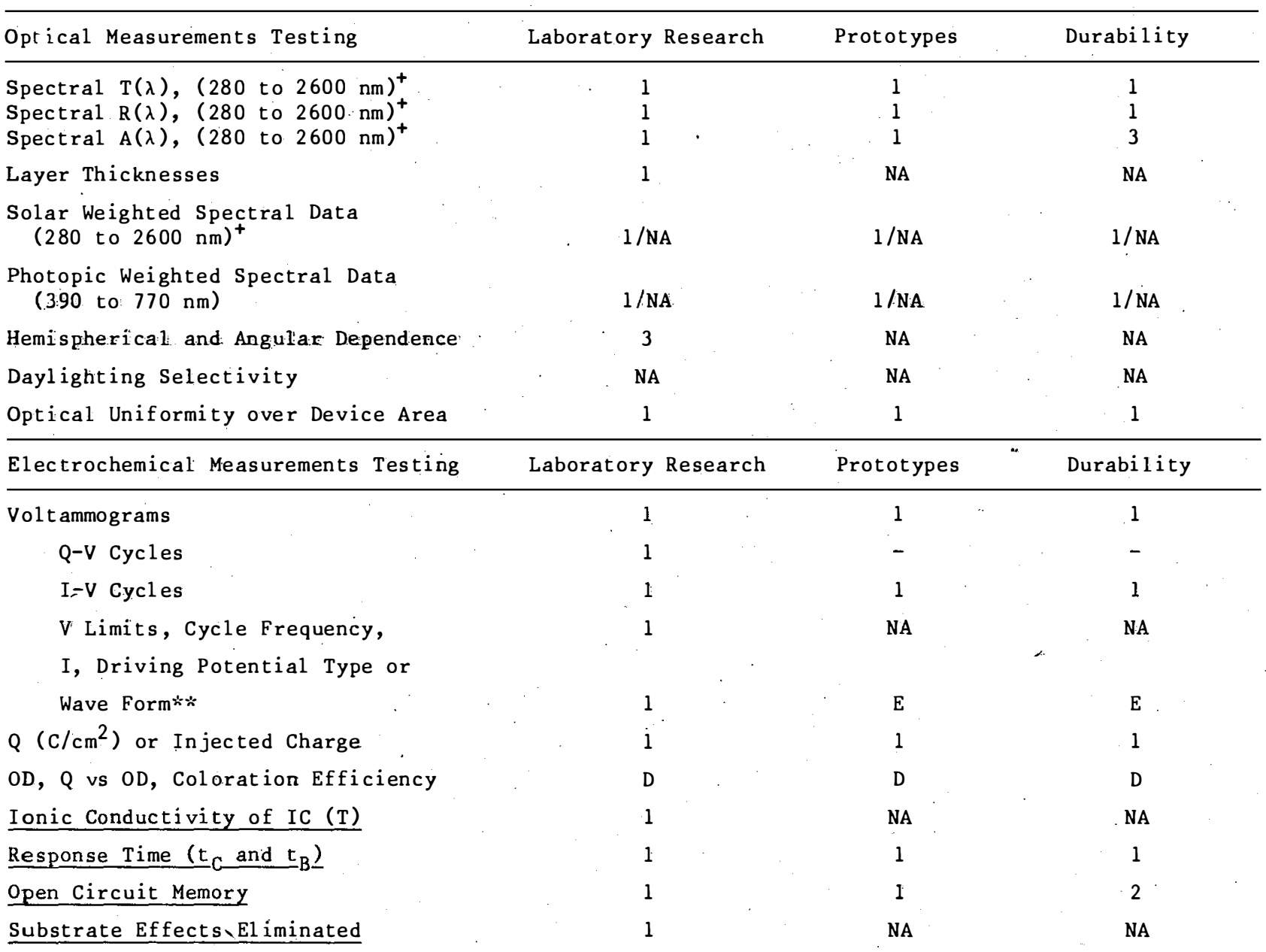

$\therefore-2$ These parameters are essential, and when determined from laboratory research, must be used without variation for prototype and durability testing.

*NA is because the quantity may be for a previously established material or device design or may be derived by reducing data from some other measurement.

${ }^{+}$In the ideal case for a reflective $\mathrm{film}, \mathrm{A}(\lambda)$ can be derived from $\mathrm{T}(\lambda)$ and $\mathrm{R}(\lambda)$, but it is best to measure $A(\lambda)$ experimentally to assure non-ideal loss mechanisms are not present. Measurements made from 350 to $2200 \mathrm{~nm}$ will result in losses of $1 \%$ and $3 \%$ of the available solar energy, resp. (Hulstrom, et a1., 1985). 
Table 6-2. Recommended Test Matrix at Various Stages of EC Window Research and Development

\begin{tabular}{|c|c|c|c|c|c|}
\hline \multirow{2}{*}{$\begin{array}{l}\text { Measurement or } \\
\text { Degradative } \\
\text { Stress }\end{array}$} & \multirow[b]{2}{*}{$\begin{array}{c}\text { Laboratory } \\
\text { Research }\end{array}$} & \multirow[b]{2}{*}{ Prototype } & \multicolumn{3}{|c|}{ Stability/Durability Testing } \\
\hline & & & Real-Time $^{+}$ & Weather-Ometer & QUV \\
\hline$T(\lambda), R(\lambda), A(\lambda)$ & $280-2600 \mathrm{~nm}$ & $280-2600 \mathrm{~nm}$ & $280-2600 \mathrm{~nm}^{-*}$ & $280-2600 \mathrm{~nm} *$ & $280-2600 \mathrm{~nm} *$ \\
\hline Optical Uniformity & Spectral & Spectral & Visual & Visual & Visual \\
\hline Layer thicknesses & -- compare lay & yer thickness vs 2 & $25^{\circ} \mathrm{C}$ after exposur & e to $100^{\circ} \mathrm{C}-$ & ------ \\
\hline Surface Analysis & Use diagnostic & cally and for dept & h profiling at/th & rough interfaces & \\
\hline $\begin{array}{r}\text { Volt ammograms } \\
\text { I-V Cycles }\end{array}$ & $\begin{array}{c}\text { Yes } \\
\text { Variable }\end{array}$ & Yes & Yes & Yes & Yes \\
\hline $\begin{array}{l}\text { V Limits } \\
\text { I Used }\end{array}$ & $\begin{array}{l}\text { Variable } \\
\text { Variable }\end{array}$ & $\begin{array}{l}\text { Values are fixed } \\
\text { changed arbitrar }\end{array}$ & $\begin{array}{l}\text { f from laboratory } \\
\text { rily }\end{array}$ & research and evaluation & and are not \\
\hline $\begin{array}{l}\text { Driving Potential Form } \\
\text { Cycle Frequency Variable }\end{array}$ & $\begin{array}{l}\text { Variable } \\
0.1,1,10 / \mathrm{h}\end{array}$ & $0.1,1,10 / \mathrm{h}$ & $0.1,1,10 / \mathrm{h}$ & $0.1,1,10 / \mathrm{h}$ & $0.1,1,10 / \mathrm{h}$ \\
\hline In jected Charge $\left(\mathrm{c} / \mathrm{cm}^{2}\right)$ & integrate time & e and current & same & same & same \\
\hline Response time $\left(t_{c}, t_{B}\right)$ & Variable & Use 84 to $16 \%^{++}$ & changes from $100 \%$ & of the possible percent & t change in $\mathrm{T}$ \\
\hline Open Circuit Memory & Measure & Note & Note & Note & Note \\
\hline Temperature & $0,27,60,100^{\circ} \mathrm{C}$ & $0,27,60,100^{\circ} \mathrm{C}$ & Variable & $60,100^{\circ} \mathrm{C}$ & $40,60^{\circ} \mathrm{C}$ \\
\hline UV & 17 suns, xenon & n simulation, 285 & - $700 \mathrm{~nm}$, except & for real-time and QUV & \\
\hline Humidity & Normal & $80 \%$ & Variable & $80 \%$ & $\begin{array}{c}\text { Condensation } \\
\text { Cycle }\end{array}$ \\
\hline Pollutants & NA & NA & $\begin{array}{c}\text { Variable } \\
\text { Site Specific }\end{array}$ & $\begin{array}{l}\mathrm{SO}_{2}, \mathrm{NO}_{2} \\
\text { Chloride, other }\end{array}$ & None \\
\hline
\end{tabular}

${ }^{+}$Real-time testing includes outdoor exposure, with and without shutters, constant elevated stagnant $\mathrm{T}$, and under simulated storage conditions

${ }^{*} \mathrm{~T}(\lambda)$ only may be monitored periodically at variable $\lambda$. An on-line continuous monitor at a fixed $\lambda$ may be successful

${ }^{++}$These correspond to two standard deviations 


\subsection{ACKNOWLEDGMENTS}

The authors thank the researchers who supplied information for this report, especially, to those whose work is cited in Tables 5-1, 5-2, and the related text and to those who provided private communications to us. The authors are also pleased to thank the following for providing extensive technical information for this document: D. K. Benson and C. E. Tracy, SERI; S. F. Cogan and R. D. Rauh, EIC Laboratories, Inc.; R. Goldner and T. Haas, Tufts University; and S. Selkowitz, LBL. Many of those cited on the distribution list also served as reviewers of a draft version of this document. The authors gratefully acknowledge their assistance and comments. The work was performed, in part, at the Lawrence Berkeley Laboratory in the Applied Science Division, and, in part, in the Photovoltaic Measurements and Performance Branch at SERI. The authors also appreciate the financial support by the Assistant Secretary for Conservation and Renewable Energy, Office of Solar Heat Technologies, Solar Buildings Division, United States Department of Energy under contracts DE-AC02-83CH10093 and DE-AC03-76SF00098. 


\subsection{REFERENCES}

Arnoldussen, T. C., (1978), "A Model for Electrochromic Tungstic Oxide Microstructure and Degradation" General Motors Research Report No. GMR-2775.

Bartovics, W. A., (1984), "The Thermal Performance of Fixed and Variable Selective Transmitters in Commercial Architecture," M.S. in Architectural Studies, Cambridge, MA: MIT.

Beni, G., C. E. Rice, and J. L. Shay, (1980), "Electrochromism of Anodic Iridium Oxide Films," J. Electrochem. Soc., vol. 127, 1342.

Beni, G. and J. L. Shay, (1980), "New electrochromism isotherm in anodic iridium oxide films," Phys. Rev. B: Condens. Matter [2], vol. $21,364$.

Beni, G. and J. L. Shay, (1982), "Ion-Insertion Electrochromic Displays," in Advances in Image Pickup and Display, vol. 5, Academic Press, N.Y.

Benson, D. K., (1989), Private communication.

Benson, D. K, and C. E. Tracy, and M. R. Ruth, (1984), "Solid State Electrochromic Switchable Window Glazings," SERI/TP-255-2435.

Benson, D. K. and J.S.E.M. Svensson, (1990), "Plasma Enhanced CVD of W and Mo Oxides," in Large Area Chromogenics: Materials and Devices for Transmittance Control, C. M. Lampert and C. G. Granqvist, eds., vol. IS4, SPIE Optical Engineering Press, Bellingham, WA, 215-229.

Benson, D. K., C. E. Tracy, J. S. E. M. Svensson, and B. E. Liebert, (1987), "Preparation of Electrochromic Metal Oxide Films by Plasma Enhanced Chemical Vapor Deposition," Proc. SPIE, vol. 823, 72.

Bryan, H., C. St. Clair, and S. Stuebing, (1984), "Optically Switched Shading," Proceedings, Buildings Innovative Concepts Fair, Arlington, VA., PNL Report No. SA-12234, May 23, Pacific Northwest Laboratories, Richland, WA, pp. 3.1-3.11.

Carlson, D. E. and C. R. Wronski, (1976), "Amorphous Silicon Solar Cells," Appl. Phys. Lett., vol. 28, 671-3.

Carpenter, M. K., R. S. Conell, and D. A. Corrigan, (1987), "The Electrochromic Properties of Hydrous Nickel Oxide," Solar Energy Mat., vol. 16, 333 .

Cogan, S. F., (1990), private communication.

Cogan, S. F., T. D. Plante, R. S. McFadden, and R. D. Rauh, (1987), "Design and Optical Modulation of a- $\mathrm{WO}_{3} / \mathrm{a}-\mathrm{IrO}_{2}$ Electrochromic Windows," Proc SPIE, 823,1060 .

Cogan, S. F. and R. D. Rauh, (1989), private communication. 
Cogan, S., and R. D. Rauh, (1990), "The a- $\mathrm{WO}_{3} / \mathrm{a}-\mathrm{IrO}_{2}$ Electrochromic System," in Large Area Chromogenics: Materials and Devices for Transmittance Control, C. M. Lampert and C. G. Granqvist, eds., SPIE Optical Engineering Press, Vol. IS4, Bellingham, WA, pp. 482-493.

Crandall, R. S. and B. W. Faughnan, (1975), "Measurement of the Diffusion Coefficient of Electrons in $\mathrm{WO}_{3}$ Films (Electrochromic Material)," Appl. Phys. Lett., vol. 26, 120.

Crandall, R. S. and B.W. Faughnan, (1976), "Dynamics of Coloration of Amorphous Electrochromic Films of $\mathrm{WO}_{3}$ at Low Voltages," Appl. Phys. Lett., vol. 28, 95 .

Crandall, R. S. and B. W. Faughnan, (1977), "Comment on the clluster model of alkali-metal tungsten bronzes," Phys. Rev. B: Solid State [16], 175:0.

Crandal1, R. S., R. J. Wojitowiiez, and B. W. Eaughinan, "Theory and Measurement of the Change in Chemical Potential of. Hydrogen in Amorphous $\mathrm{H}_{x} \mathrm{WO}_{3}$ as a Function of the Stoichiometric Parameter $\mathbb{R}$ (1976), Solid State Commun., vol. 18, 1409-11.

Cunningham, R. C., (1986), "Glass Market Future Looks Good," Glass Digest, May 15, 1986, Ashlee Publishing Co., New York: p. 76.

Czanderna, A. W. (ed.), (1975), Methods of Surface Analysis, Elsevier, Amsterdam.

Dautremont-Smith, W. C., L.M. Schiavone, S. Hackwood, G. Beni, and J. L. Shay, (1980), "Electrochromic Cells with Iridium Oxide Display Electrodes," Solid State Ionics, vol. 2, 13.

Faughnan, B. W. and R. S. Cranda11, (1980), "Electrochromic Displays Based on WO $_{3}$," Display Devices, J. I. Pankove, ed., Springer-Verlag, Berlin, 18I-211.

Faughnam, B. W.. R.. S. Gramdall, and P. M. Heyman, (1975), "Electrochromism in WO $_{3}$ Amorphous Films," RCA Rev. vol. 36, 177.

Fleissch, T: H. and F. J. Mains, (1982), "Ain XPS Study of the Reduction and Photochromism of: $\mathrm{MoO}_{3}$ and $\mathrm{WO}_{3}$," J. Chem. Ekys.., vol. ?6, 780..

Giglia, R.D. and G. Haacke, (1982), "Performance. Improvements in $\mathrm{WO}_{3}$ Based Electrochromic Displays," Proc. SID, vol. 23', 4'."

Gissler, W. and R. Memming, (1977), "Photoelectrochemical Processes at Semiconducting $\mathrm{WO}_{3}$ Layers," J. Electrochem. Soc., vol. 124, 1710.

Goldner, R. B., G. Berera, F. O. Arntz, T. E. Haas, B. Morel, and K. K. Wong, (1990), "Reflectivity, Modulation with Electrochromic $\mathrm{Li}_{\mathrm{x}} \mathrm{WO}_{3} \mathrm{Films,"} \mathrm{in}$ Electrochromic Materials, M. K. Carpenter and D. A. Corrigan, eds., The Electrochemical Society, vol. 90-2, Pennington, NJ, p. 14.

Goldner, R. B., G. Seward, K. Wong, T. Haas, G. H. Foley, R. Chapman, and S. Schultz, (1989), "Completely Solid Lithiated Smart Windows," Solar Energy Mat., vol. 19, 17-26. 
Hackwood, S., A. H. Dayem, and G. Beni, (1981) Bull. Am. Phys. Soc. [2], vol. 26,215 .

Hackwood, S., G. Beni, W. C. Deutremont-Smith, L. M. Schiavone, and J. L. Shay, (1980), Appl. Phys. Lett., vol. 37, 965.

Hajimoto, Y., M. Matsushima, and S. Ogura, (1979), "Solid State Electrochromism in $\mathrm{WO}_{3}, " \mathrm{~J}$. Electron. Mat., vol. 8, 301.

Hari, Y. and C. Tani, (1983), "Electrochromism for Organic Materials in Polymeric All solid State System," Appl. Phys. Lett., vol. 43, 704.

Hitchman, M. L., (1977), "Analysis of Equilibrium Potentials of Hydrogen Tungsten Bronzes," J. Electroanal. Chem. Interfacial Electrochem., vol. 85,135 .

Hulstrom, R., R. Bird, and C. Riordan, (1985), "Spectral Solar Irradiance Data Sets for Selected Terrestrial Conditions," Solar Cells, vol. 15, 365-391.

Hughes, A. J. and P. Lloyd, (1977), "Solid State Electrochromism in $\mathrm{WO}_{3}, " \mathrm{~J}$. Electron. Mat., vol. 6, 752.

Jorgensen, G. and P. Schissel, (1989), "Optical Performance and Durability of Silvered Polymer Mirrors," in Metallized Plastics I," K. L. Mittal and J. R. Susko, eds., Plenum, N.Y., 79-92.

Kamimori, T., J. Nagai, and M. Mizuhashi, (1987), "Electrochromic Devices for Transmissive and Reflective Light Control" Solar Energy Mat., vol. 16, 27.

Kase, T., M. Kawai, and M. Ura, (1986), "A New Electrochromic Device for Automotive Glass-The Development of Adjustable Transparency Glass," Proc. SAE Meeting, Sept. 22-25, 1986, and private communications with Nissan Motors.

Knowles, T. J., (1977), "Optical Regeneration of Aged WO 3 Electrochromic Cells," Appl. Phys. Lett., vol. 31, 817.

Lampert, C. M., (1981), "Heat Mirror Coatings for Energy Conserving Windows," Solar Energy Mat., vol. 6, 41.

Lampert, C. M., (1984), "Electrochromic Materials for Windows and Devices for Energy Efficient Windows," Solar Energy Mat., vol. 11, 1-27.

Lampert, C. M., (1990a), "Evaluation and Characterization Parameters for Electrochromic Devices," IEA Study, LBL Report, to be published.

Lampert, C. M., (1990b) "Chemical and Optical Studies of Electrochromic Hydrated Nickel Oxide Films and Devices," in Large-Area Chromogenics: Materials and Devices for Transmittance Control, C. M. Lampert and C. G. Granqvist, eds., SPIE Optical Engineering Press, vol. IS4, Bellingham, WA, 414-446.

Lampert, C.M., (1990c), "Durability of Electrochromic Switching Devices for Glazings," Proc. SPIE, 1272, in press. 
Lampert, C. M. and C. Granqvist, (eds.), (1990), Large Area Chromogenics: Materials and Devices for Transmittance Control, SPIE Optical Engineering Press, vol. IS4, Bellingham, WA, (in press).

Luft, W. and S. Tsuo, (1988), "Plasma Deposition of Hydrogenated Amorphous Silicon Films," Appl. Phys. Commun., vol. 8, 1-74 with 213 references.

Lusis, A. R., Y.. K. Klayavin, Y. Y. Kleperis, Y. Y. Pinnsi, and O. A. Rode, (1982), "Electrochemical Processes in Solid Electrochromic Systems," Elektrokhimiya, vol. 18, 1538.

Lusilis;, A. R., J. J. Kleperis, A. A. Brishka, and E. V. Pentyush, (1984), "Electro-optic Spectroscopy of Electrochromic Processes in Tungsten Trioxide," Solid State Ionics, vol. 13, 319.

Madan, A., (1986), "Amorphous Silicon: From Promise to Practice," The IEEE Spectrum, vol. 23, [9], 38-43.

Masumi, T., K. Normura, K. Nishioka, H.e Deguchi, and H. Ono, (1982), SID Digest, vol. 13, 100.

Masterson, K., A. W. Czanderna, J. Blea, R. Goggin, M. Guiterrez, G. Jorgensen, and J. McFadden, (1983), "Matrix Approach to Testing Mirrors-Part 2," SERI/TR-255-1627, Solar Energy Research Institute, Golden, CO.

Mohapatra, S., (1978), "Electrochromism in $\mathrm{Li}_{\mathrm{x}} \mathrm{WO}_{3}, "$ J. Electrochem. Soc., vol. 125,284 .

Morita, H. and H. Washida, (1982), "Considerations on the Degradation of Electrochromic Display Using Tungsten Oxide," Oyo-Butsuri, vol. 50, 488.

Nagai, J., T. Kamimori, and M. Mizuhashi, (1984), "Mechanism of Long Term Change in Electrochromism of $\mathrm{Li}_{x} \mathrm{WO}_{3}$ Films," Proc. SPIE, vol. 502, 59.

Nagai, J., T. Kamimori, and M. Mizuhashi, (1986a), "Electrochromism in Amorphous Lithium Tungsten Oxide Films," Solar Energy Mat., vol. 13, 279.

Nagai, J., T. Kamimori, and M. Mizuhashi, (1986b), "Transmissive Electrochromic Device," Solar Energy Mat., vol. 14, 175.

Oi, T., (1986), "Electrochromic Materials," Ann. Rev. Mat. Sci., vol. 16, 185.

Pennisi, A. and C. M. Lampert, (1988), "Optical Properties of Electrochromic Nickel Oxide Devices Utilizing A Polymeric Electrolyte," Proc. of SPIE, to be published.

Poate, J., K. N. Tu, and J. W. Mayer, eds., (1978), Interdiffusion in Thin Films, Wiley, N.Y.

Randin, J. P., (1978), "Chemical and Electrochemical Stability of Electrochromic Films in Liquid Electrolytes," J. Electron. Mat., vol. 7, 47. 
Reilley, S., S. D. Arasteh, and S. Selkowitz, (1990), "Thermal and Optical Analysis of Switchable Window Glazings," Solar Energy Mat., vol. 20, in press.

Robin, M. B. and P. Day, (1967), Adv. Inorg. Chem. Radiochem., vol. 10, 247.

Schissel, P. and H. H. Neidlinger, (1987), "Polymer Reflector Research During FY 1986," SERI/PR-255-3057, Solar Energy Research Institute, Golden, CO.

Schlotter, P. and L. Pickelmann, (1982), "The Xerogel Structure of Thermally Evaporated Tungsten Oxide Layers," J. Electron. Mat., vo1. 11, 207.

Selkowitz, S. E. and C. M. Lampert, (1990), "Application of Large Area Chromogenics to Architectural Glazings," in Large-Area Chromogenics: Materials and Devices for Transmittance Control, C. M. Lampert and C. G. Granqvist, eds., SPIE Optical Engineering Press, Vol. IS4, Bellingham, WA., pp. 22-45.

Seward, G., R. B. Goldner, K. Wong, T. Haas, G. H. Foley, R. Chapman, and S. Schultz, (1987), "Optical Materials for Energy Efficiency and Solar Energy Conversion VI," SPIE, vol. 823, Bellingham, WA, 90-100.

Shirmer, O. F., V. W. Hwer, G. Baur, and G. Brandt, (1977), "Dependence of $\mathrm{WO}_{3}$ Electrochromic Absorption on Crystallinity," J. Electrochem. Soc., vol. 124 749 .

Smakula, A., (1930), Z. Phys., vol. 59, 609.

Stocker, H. J., S. Singh, L. G. Van Uitert, and G. Zydzik, (1978), "Efficiency and Electro-optic Properties of all Solid State $\mathrm{WO}_{3}$-LiF Electrochromic Sandwich Structure," J. Electron. Mat., vol. 7, 707.

Svensson, J. S. E. M. and C. G. Granqvist, (1987), "Electrochromism of Nickel-Based Sputtered Coatings," Solar Energy Mat., vol. 16, 19.

Yoshimura, T., M. Watanabe, K. Kitota, and M. Tanaka, (1982), "Electrolysis in Electrochromic Device Consisting of $\mathrm{WO}_{3}$ and $\mathrm{MgF}_{2}$ Thin Films," Jap. J. of Appl. Phys., vol. 21, 128 .

Yu, P. C., G. Nazri, and C. M. Lampert, (1987), "Spectroscopic and Electrochemical Studies of Electrochromic Hydrated Nickel Oxide Films," Solar Energy Mat., vol. 16, 1.

Webb, J. D., P. Schissel, T. M. Thomas, J. R. Pitts, and A. W. Czanderna, (1984), "Polymer Degradation on Reflecting Metal Films: Fourier Transform Infrared Reflection-Absorbance Studies," Solar Energy Mat., vol. 11, 163-175.

Weppner, W. and H. Schultz, eds., (1987), Solid State Ionics, North Holland, Amsterdam.

Wolsky, S. P., J. L. Vossen, R. S. Crandall, and D. M. Blake, (1988), private communication. 


\section{SELECTED DISTRIBUTION LIST}

Mr. Greg Ander

SCE Company

Room 391

2244 Walnut Grove Avenue

Rosemead, CA 91770

Dr. Abraham Belkind

Senior Physicist

The BOC Group, Technical Center

100 Mountain Ave.

Murray Hill, NJ 07974

Dr. Harlan J. Byker

Dir. Electrochem. Dev.

Gentex Corporation

10985 Chicago Dr.

zeeland, MTI 4:4:64

Mr. John: Chapin

Vice President, $R \& D$

Applied Eilms Eabi, Inc.

67.97 Winchester Circle

Boulder, CO 80301

Mr. Randy Chang

CRE Division

U.S. Department of Energy

San Francisco Operations Office

1333 Broadway

Oalkliand, CA 946,12

Mr : Rusisel Clark

Dïr., Advanced Engineering

Prince Corp.

1 Prince Center

Holland, MI 49423

Dr. Stuart F. Cogan

EIC Laboratories, Inc.

111 Downey Street

Norwood, MA 02062

Dr. K. Collier

Florida Solar Energy Center

300 State Road 401

Cape Canaveral, FL 32920
Dr. A. W. Czanderna

Solar Energy Research Institute

1617 Cole Boulevard

Golden, CO 80401

(303) 231-1240

Dr. Hul ya Demiryont

Ford Motor Co., Glass Research Div. 15000 Commerce Dr., N.

Dearborn, MI 48120

Mr. A. Fickett

Electric Power Research Inst.

P.0. Box 10412 \#

Palo Alto, CA 94303

Mr. Robert Goff

$3 \mathrm{M}$ Corporation

B1dg. 224-2S-25, 3M Center

St. Paul, MN 55144-1000

Dr. Ronald B. Goldner \#

Electro-Optic:s Technology Center

Halligan Hall

Tufts University

Medford, MA 02155

Dr. John C. Goldsmith

U.S. Department of Energy

CE-421, Room 5H-047

1000 Independence: Ave., S.W.

Washingtom, DC: 20585

Mr. J. W. Griffith

National Fenestration Council

3921 Caruth Boulevard

Dallas, TX 75225

Dr. Ahsan Habib

General Motors Research

30500 Mound Road

Warren, MI 48090-9055

Mr. Robert J. Hassett

U.S. Department of Energy

CE-421, Room 5H-047

1000 Independence Ave., S.W.

Washington, DC 20585 


\author{
Mr. Jim Hill \\ National Institute of Science \\ and Technology \\ Technology B-148 \\ Gaithersburg, MD 20899 \\ Mr. Douglas Hittle \\ Colorado State University \\ Solar Energy Applications Lab \\ Fort Collins, CO 80523 \\ Mr. Thomas G. Hood \\ Manager, Product Dévelopment \\ Southwall Technologies \\ 1029 Corporation Way \\ Palo Alto, CA 94303 \\ Mr. Robert Hughey \\ DOE/San Francisco \\ Wells Fargo Building \\ 1333 Broadway \\ Oakland, CA 94612 \\ Ms. Mary Margaret Jenior \\ CE-421, Room 5H-047/FORS \\ U.S. Department of Energy \\ 1000 Independence Avenue, S.W. \\ Washington, D.C. 20585 \\ (202) 586-2998
}

Mrs. Annette Johncock-Krisko

Research Scientist

Ford Motor Co., Glass Research Div. 15000 Commerce Dr., N.

Dearborn, MI 48120

Mr. William Kallman

President

Eyeonics

3740 S. W. Calden

Portland, OR 97219

Mr. Rom Kammerud

Lawrence Berkeley Laboratory

Mail Stop-90-2056

One Cyclotron Road

Berkeley, CA 94720

Mr. Theodore E. Kapus, Director Office of Building Energy Research CE-42

U.S. Department of Energy

1000 Independence Ave., S.W.

Washington, DC 20585
Mr. Ted L. Kurkowski

U.S. Department of Energy

CE-30.1, Room 6C-026

1000 Independence Ave., S.W.

Washington, DC 20585

Dr. Carl M. Lampert

Lawrence Berkeley Laboratory

Applied Science Division

1 Cyclotron Rd, B1dg. 62

University of California

Berkeley, CA 94720

(415) 486-6093

Dr. James N. Lingscheit

Vice President

Airco Coating Technologies, Inc.

4020 Pike Lane

P.0. Box 4105

Concord, CA 94524

Mr. Larry Loerch

Manager, Business Development

$M \& \mathrm{~T}$ Chemical Co.

1 Woodbridge Road

Woodbridge, NJ 07095

Dr. Niall R. Lynam

Donnelly Corporation

414 East 40 th Street

Holl and, MI 49423

Dr. John P. Millhone

CE-40, Room 5E-080

U.S. Department of Energy

1000 Independence Avenue, S.W.

Washington, D.C. 20585

Dr. R. David Rauh

Vice President, Director of Research

EIC Laboratories, Inc.

111 Downey Street

Norwood, MA 02062

Dr. Sue Reilly

Lawrence Berkeley Laboratory

Applied Science Division

University of California

Berkeley, CA 94720

Mr. Arthur Rosenfeld

Lawrence Berkeley Laboratory

University of California

Berkeley, CA 94720 


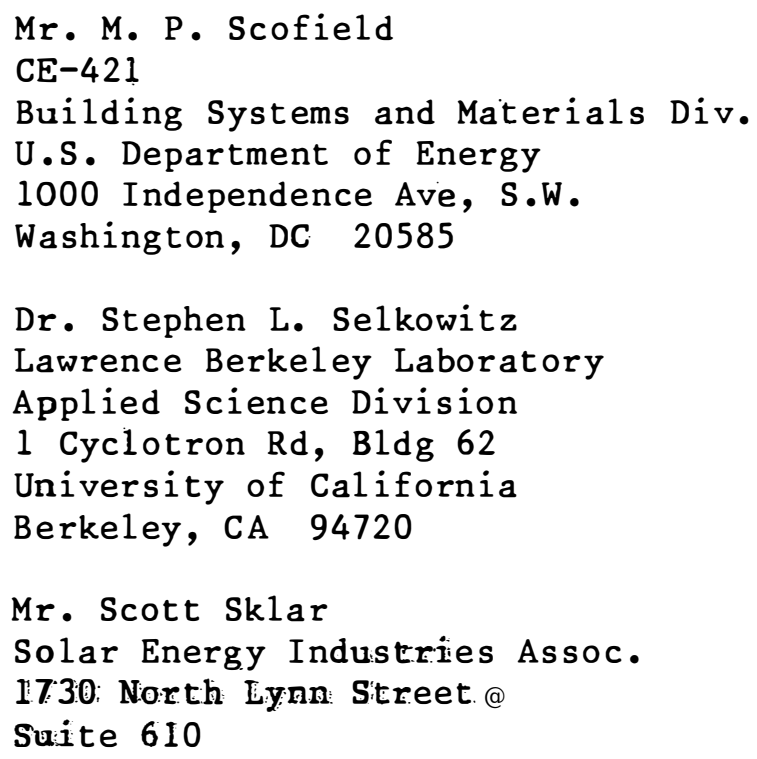

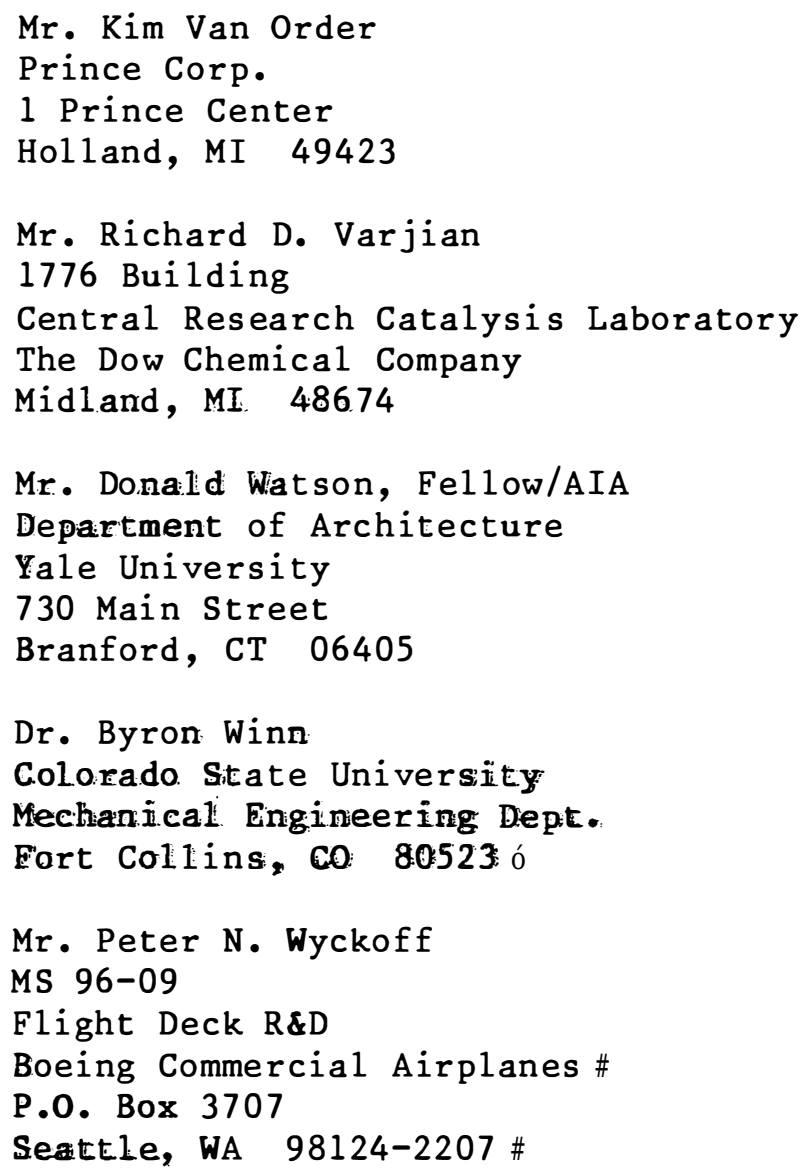

\section{SERI Distribution}

Dr. R. Anderson, 2540

Dr. M. L. Murphy, 2500 \#

Dr. J. L. Stone, 2100 ó

Dr. S. K. Deb, 2120

Dr. L. L. Kazmerski, 2130 \#

Dr. R. S. Cranda 11,2120

Mr. D. K. Benson, 2120

Mr. C. E. Tracy, 2120

Author (20) 


\begin{tabular}{|c|c|c|}
\hline $\begin{array}{c}\text { Document Control } \\
\text { Page }\end{array}$ & $\begin{array}{c}\text { 1. SERI Report No. } \\
\text { SERI/TP-255-3537 }\end{array}$ & $\begin{array}{c}\text { 2. NTIS Accession No. } \\
\text { DE90000334 }\end{array}$ \\
\hline
\end{tabular}

4. Title and Subtitle $P$

Evaluation Criteria and Test Methods for

Electrochromic Windows

3. Recipient's Accession No. P.

5. Publication Date

July 1990

6.

7. Author(s) $\mathrm{P}$

A. W. Czanderna, C. M. Lampert

9. Performing Organization Name and Address

Solar Energy Research Institute

1617 Cole Boulevard

Golden, CO 80401

8. Performing Organization Rept. No.

SERI/TP-255-3537

10. ProjecVTask/Work Unit No.

SB913041

11. Contract (C) or Grant (G) No.

(C) $\mathrm{DE}-\mathrm{ACO} 2-83 \mathrm{CH} 10093$

(G)

12. Sponsoring Organization Name and Address

Solar Energy Research Institute

1617 Cole Boulevard

Golden, CO 80401

13. Type of Report \& Period Covered Technical Report

14.

15. Supplementary Notes

16. Abstract (Limit: 200 words)

Report summarizes the test methods used for evaluating electrochromic (EC) windows, and summarizes what is known about degradation of their performance, and recommends methods and procedures for advancing EC windows for buildings applications.

17. Document Analysis

a. Descriptors electrochromic windows, performance degradation, evaluation criteria, performance criteria, test methods,. EC windows

b. Identifiers/Open-Ended Terms

c. UC Categories 316

18. Availability Statement

National Technical Information Service

U.S. Department of Commerce

5285 Port Royal Road

Springfield, VA $221 \overline{6} 1$
19. No. of Pages

61

20. Price

$\mathrm{A04}$ 